\title{
Review Article \\ Essential Oils and Their Constituents as Anticancer Agents: A Mechanistic View
}

\author{
Nandini Gautam, ${ }^{1}$ Anil K. Mantha, ${ }^{2}$ and Sunil Mittal ${ }^{1}$ \\ ${ }^{1}$ Centre for Environmental Science and Technology, School of Environment and Earth Sciences, Central University of Punjab, \\ Bathinda, Punjab 151001, India \\ ${ }^{2}$ Centre for Biosciences, School of Basic and Applied Sciences, Central University of Punjab, Bathinda, Punjab 151001, India \\ Correspondence should be addressed to Anil K. Mantha; anilmantha@gmail.com and Sunil Mittal; sunil.cevs@gmail.com
}

Received 26 February 2014; Accepted 11 April 2014; Published 9 June 2014

Academic Editor: Kota V. Ramana

Copyright (C) 2014 Nandini Gautam et al. This is an open access article distributed under the Creative Commons Attribution License, which permits unrestricted use, distribution, and reproduction in any medium, provided the original work is properly cited.

Exploring natural plant products as an option to find new chemical entities as anticancer agents is one of the fastest growing areas of research. Recently, in the last decade, essential oils (EOs) have been under study for their use in cancer therapy and the present review is an attempt to collect and document the available studies indicating EOs and their constituents as anticancer agents. This review enlists nearly 130 studies of EOs from various plant species and their constituents that have been studied so far for their anticancer potential and these studies have been classified as in vitro and in vivo studies for EOs and their constituents. This review also highlights in-depth various mechanisms of action of different EOs and their constituents reported in the treatment strategies for different types of cancer. The current review indicates that EOs and their constituents act by multiple pathways and mechanisms involving apoptosis, cell cycle arrest, antimetastatic and antiangiogenic, increased levels of reactive oxygen and nitrogen species (ROS/RNS), DNA repair modulation, and others to demonstrate their antiproliferative activity in the cancer cell. The effect of EOs and their constituents on tumour suppressor proteins (p53 and Akt), transcription factors (NF- $\kappa$ B and AP-1), MAPK-pathway, and detoxification enzymes like SOD, catalase, glutathione peroxidase, and glutathione reductase has also been discussed.

\section{Introduction}

Cancer has emerged as one of the most alarming diseases in the last few decades throughout the world. It is a multifactorial disease contributing towards uncontrolled growth and invasion of the abnormal cells leading to the formation of tumour. The steep rise in the number of cancer cases may be attributed to the change in food habits, use of tobacco and alcohol, chronic infections, exposure to harmful radiations and chemicals, or more widely due to change in lifestyle and environmental pollution [1]. International Agency for Research on Cancer (IARC) reported that there are approximately 12 million cancer cases and these have accounted for 7.6 million deaths (around 13\% of all deaths) in the year 2008 [2]. The recent estimates reveal that the number of new cancer cases and cancer-related deaths has increased by $11 \%$ and 7.9 , respectively, in the year 2012 as compared to 2008 [2]. Further, the developing countries have half the number of cancer incidence cases compared to the developed countries [3]. In India, 0.979 million cancer cases were reported in the year 2010 which is expected to increase to 1.148 million by 2020 [4]. The mortality rate among cancer patients is very high. The problem is more serious in economically less developed countries due to the lack of diagnostic techniques, standard methods of treatment, and higher cost of the treatment [5]. People in scientific field are currently overcoming these problems with the use of synthetic drugs. These drugs are designed to specifically target rapidly growing and dividing cells of various tumours. But, these synthetic drugs also affect rapidly dividing normal cells in our body leading to certain other major irreversible side effects. Chemotherapy used in cancer treatment has been reported to induce multidrug resistance 
$[6,7]$. The high cost, increasing drug resistance, and side effects of current therapeutic approaches are forcing the scientists to explore alternative medicines, the traditional medicine, as an option to find new chemical entities for treatment of cancer.

Among the alternative traditional approaches, various plant products classified as alkaloids, saponins, triterpenes, glycosides, and polyphenols among others have shown very promising anticancer properties in both in vitro and in vivo. There are more than one thousand plants which have been reported to possess significant anticancer properties [8]. Vincristine, vinblastine, colchicine, ellipticine, lepachol, taxol, podophyllotoxin, camptothecin, irinotecan, etoposide, and paclitaxel are classical examples of plant-derived compounds which are found to have wide applications in cancer therapeutics [9]. The plant-derived products are expected to induce lesser side effects compared to synthetic drugs. Among plant derived compounds, essential oils (EOs) from aromatic plants have been reported to possess anticancer properties [10, 11]. EOs have also been reported to improve the quality of life of the cancer patients by lowering the level of their agony [12]. EOs-mediated therapy cannot be a substitute to the standard chemotherapy and radiotherapy but can be used in combination with cancer therapy to decrease the side effects of the drugs. Hence, EOs can be used for improving the health of the cancer patients and as a source of novel anticancer compounds. In the last two decades, a number of researches are exploring anticancer potential of EOs and their components in vitro and in vivo models. Recently, Bhalla et al. reviewed EOs as anticancer agents limiting to the recent literature and a short mechanism(s) of action [13]. However, the current review is a comprehensive one, enlisting nearly 130 studies of EOs from various plant species and their constituents that have been studied so far for their anticancer potential. The studies have been classified as in vitro and in vivo for EOs and their constituents. The current review also highlights in-depth various mechanisms of action of different EOs reported in the treatment strategies for different cancers.

\section{Chemical Classification, Uses, and Therapeutic Potential of EOs and Their Constituents}

EOs are the concentrated hydrophobic liquids with specific aroma produced by aromatic plants [14]. These are also called volatile oils or ethereal oils and are the secondary metabolites present in lower amounts in various plant parts. The composition and other biological properties of the EOs depend on their constituents. The constituents may be terpenes, aromatic compounds and some other compounds of various origins. The constituents of the EOs have been classified on the basis of their chemical structures. EOs are considered more potent than their constituents [15] due to their synergistic and more selective effect. In addition, EOs from plants growing in varied environments differ in their composition and hence have different uses. A general classification based on chemical structures along with examples is enlisted in Table 1.
EOs and their components are used for their specific aromas in perfumery and as flavouring agents in food products since ancient times. EOs have also been used in aromatherapy for improving the health due to sedative and stimulant properties. EOs are used for massage, bath, and inhalation as relaxants and treatment options as aromatherapies for various diseases with active ingredients that are being exploited in medicine [16]. The lipophilic nature of these EOs enables them to easily cross the membranes of the cells and reach inside the cell. EOs are described as strong antioxidants [10,17] and antimicrobial [18] and are in use for the management of severe diseases like cardiovascular [19], diabetes [20], Alzheimer's [21], cancer [22], and others. However, the present review focuses only on the anticancer potential of EOs and their constituents.

\section{EO and Constituents as Anticancer Agents}

EO is one among the most valuable plant products used in the medicine and complementary treatment strategies. Exploration of EOs and their constituents toward their beneficial role in different cancers is currently under lens. A search of PubMed (http://www.pubmed.gov/), the National Institute of Health's online research shows 543 results for the search "cancer-essential oils" as of February 2014. Further screening of these research papers, nearly 135 correspond to anticancer properties of EO. Out of these 135 research papers, 117 have been published after the year 2005 indicating the sharp increase in number of publications in this field. EOs from different plants have been reported to have anticancer potential against mouth, breast, lung, prostate, liver cancer, colon cancer, and brain cancer and even in leukemia [23-28]. Not only EOs but their constituents like Carvacrol [29], dlimonene [30], Geraniols [31-33], Myrcene [34, 35], perillyl alcohol (POH) [36], $\alpha$-humulene [37], $\beta$-caryophyllene [38], Thymol [39, 40], Citral [41], and others have also been reported to possess cytotoxic effect on the cancer cell lines and in vivo studies. Some of these like $\mathrm{POH}$ have gone through phase I [42] and phase II [43] clinical trials in cancer patients. Terpene analogues like Terpinen-4-ol have also been reported to have anticancer properties and induce apoptosis [44].

The current review has extensively collected and documented the available studies indicating EOs from many plants and their constituents as anticancer agents. The overall literature has been divided into different tables. Tables 2 and 3 document the in vivo and in vitro studies of EOs extracted from different plants against different cell lines along with the mechanism reported. Similarly, Table 4 documents in vivo and in vitro studies of constituents of EOs.

\section{Mechanism of Action of EOs}

Drugs used in cancer treatment target the cancer cell by inducing apoptosis or cell cycle arrest. Hence, natural products causing apoptosis in the cancer cells are valuable resources in cancer suppression. EOs with therapeutic potential can act by two ways-chemoprevention and cancer suppression. Various mechanisms involved in cancer treatment are 
TABLE 1: Chemical classification, general formula, and structure of EO constituents with examples.

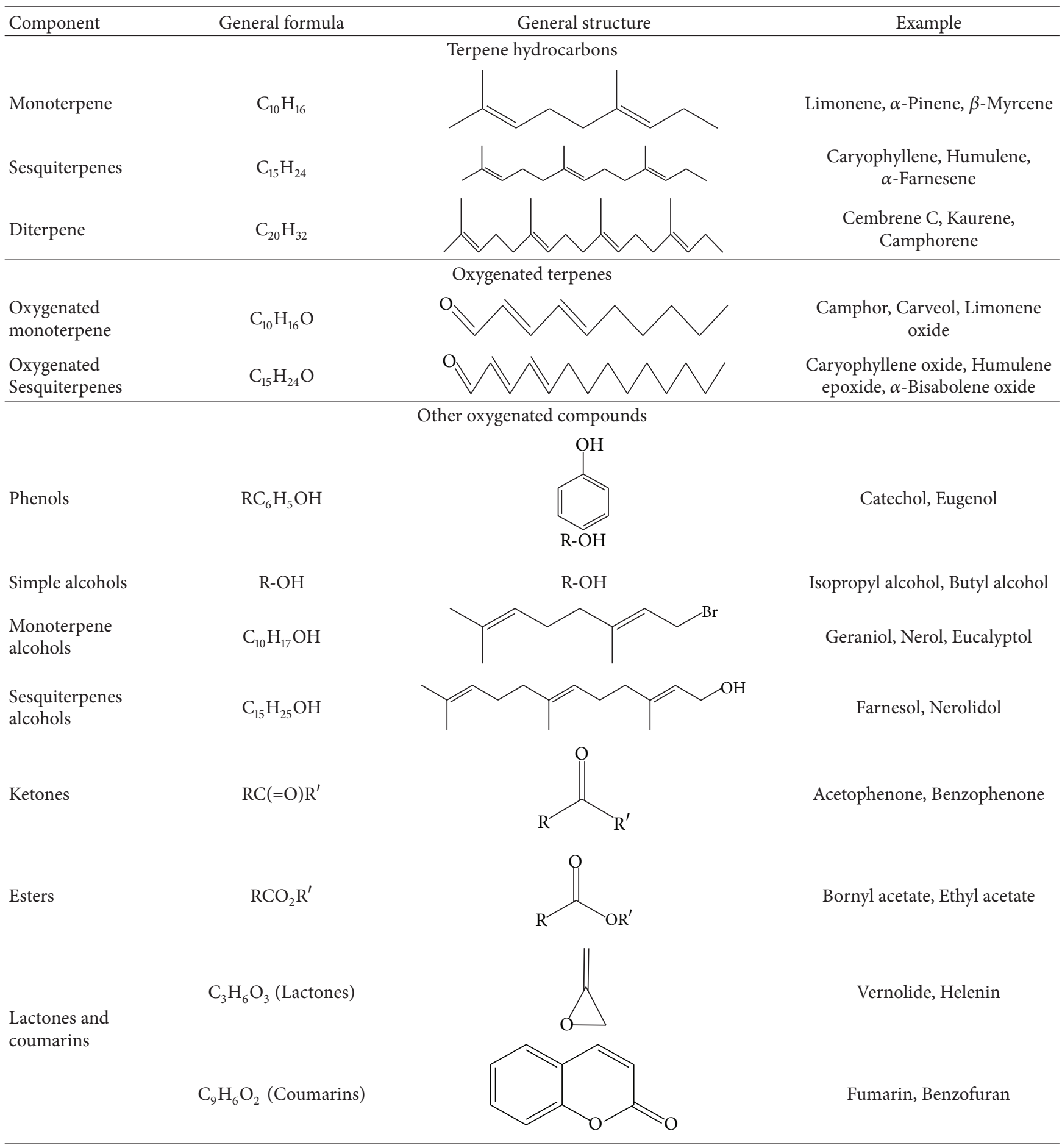

activation of detoxification enzymes, modulation of DNA repair signaling, antimetastasis, and antiangiogenesis. Multiple pathways are involved in the antiproliferative activity demonstrated by the EOs in the cancer cells and EOs are even effective in reduction of tumours in animal models. Various targets of EOs for cancer prevention are represented in Figure 1. This makes EOs suitable anticancer agents with no large apparent effects being displayed on the normal cells. Attempts have been made to study various modes of inhibition of cancer cell growth by the EOs in this section.

4.1. Induction of Apoptosis. Apoptosis can occur due to effect on various signaling pathways, genetic material, and other cellular events like changes in the proteins at the intracellular 
TABLE 2: List of EO bearing plants studied for anticancer potential in in vitro models and major observations reported.

\begin{tabular}{|c|c|c|c|}
\hline EO bearing plants & Model system & $\begin{array}{l}\text { Major } \\
\text { findings/mechanism(s) } \\
\text { reported }\end{array}$ & Reference \\
\hline Citrus limettioides & Colon cancer (SW480) cells & $\begin{array}{l}\text { Apoptosis via caspase- } 3 \\
\text { activation and inhibition of } \\
\text { cox- } 2 \text { and IL- } 6 \text {, } \\
\text { inflammatory proteins }\end{array}$ & {$[24]$} \\
\hline Pulicaria jaubertii & $\begin{array}{l}\text { Human breast (MCF-7) and liver (HepG2) } \\
\text { cancer cell lines }\end{array}$ & Cytotoxicity & {$[112]$} \\
\hline Drimys angustifolia Miers and D. brasiliensis & $\begin{array}{l}\text { Human bladder carcinoma (T24) and } \\
\text { glioblastoma (U-138 MG) cell lines }\end{array}$ & Apoptosis & {$[25]$} \\
\hline $\begin{array}{l}\text { Boswellia carterii and Commiphora } \\
\text { pyracanthoides }\end{array}$ & $\begin{array}{l}\text { Human breast (MCF-7) and hepatocellular } \\
\text { (HepG2) and cervical (HeLa), skin (HS-1) and } \\
\text { small cell lung (A549) cancers cell lines }\end{array}$ & Cytotoxicity & {$[113]$} \\
\hline Cymbopogon citratus and C. nardus & $\begin{array}{l}\text { Human breast cancer (MCF-7) and } \\
\text { non-tumorigenic (Vero) cell lines }\end{array}$ & Cytotoxicity & {$[114]$} \\
\hline Tarchonanthus camphoratus & $\begin{array}{l}\text { Human embryonic kidney and hepatocellular } \\
\text { carcinoma cells }\end{array}$ & Cytotoxicity & {$[26]$} \\
\hline Salvia officinalis L. & $\begin{array}{l}\text { Human melanoma (A375, M14, and A2058) } \\
\text { cell lines }\end{array}$ & Antiproliferative activity & {$[115]$} \\
\hline Thymus linearis and T. serpyllum & $\begin{array}{l}\text { Human breast (MCF-7), hormone dependent } \\
\text { prostate carcinoma (LNCaP) and fibroblast } \\
\text { (NIH-3T3) cell lines }\end{array}$ & Antiproliferative activity & {$[90]$} \\
\hline Porcelia macrocarpa & $\begin{array}{l}\text { Murine melanoma (B16F10-Nex2), human } \\
\text { glioblastoma (U87), cervical carcinoma (HeLa), } \\
\text { leukemia (HL-60), colon carcinoma (HCT), } \\
\text { breast adenocarcinoma (SKBr), and melanoma } \\
\text { (A2058); and non-tumorigenic (HFF) cell lines }\end{array}$ & Cytotoxicity & {$[116]$} \\
\hline Thymus fallax & $\begin{array}{l}\text { Human colorectal cancer (DLD-1) and mouse } \\
\text { fibroblast (L929) cell lines }\end{array}$ & $\begin{array}{l}\text { Cytotoxic to cancer but not } \\
\text { to normal fibroblast cells }\end{array}$ & {$[117]$} \\
\hline Achillea wilhelmsii C. Koch & $\begin{array}{l}\text { Human chronic myelogenous leukemia (K562), } \\
\text { prostate adenocarcinoma (PC3), umbilical vein } \\
\text { endothelial (HUVEC) and cervix carcinoma } \\
\text { (HeLa) cell lines }\end{array}$ & $\begin{array}{l}\text { Cytotoxic to cancer but not } \\
\text { to normal HUVEC cells }\end{array}$ & {$[118]$} \\
\hline Ducrosia anethifolia and D. flabellifolia & $\begin{array}{l}\text { Human cancer (K562, LS180 and MCF-7) cell } \\
\text { lines }\end{array}$ & Cytotoxicity & {$[119]$} \\
\hline Xylopia frutescens & $\begin{array}{l}\text { Ovarian adenocarcinoma (OVCAR-8), } \\
\text { bronchoalveolar lung (NCI-H358M) and } \\
\text { metastatic prostate carcinoma (PC-3M) cell } \\
\text { lines }\end{array}$ & Cytotoxicity & {$[120]$} \\
\hline Annona muricata & Human breast cancer (MCF-7) cell lines & Cytotoxicity & [121] \\
\hline Lippia gracilis & $\begin{array}{l}\text { Mouse melanoma (B16-F10), human } \\
\text { hepatocellular carcinoma (HepG2), and } \\
\text { chronic myelocytic leukemia (K562) cell lines }\end{array}$ & $\begin{array}{l}\mathrm{G}_{1} \text { phase arrest and } \\
\text { apoptosis via } \\
\text { caspase-dependent } \\
\text { pathway }\end{array}$ & {$[22]$} \\
\hline Cedrelopsis grevei & Human breast cancer cells (MCF-7) cell lines & Cytotoxicity & {$[122]$} \\
\hline Libanotis transcaucasica & $\begin{array}{l}\text { Human cervical adenocarcinoma (HeLa), } \\
\text { colon adenocarcinoma (LS180), breast } \\
\text { adenocarcinoma (MCF-7) and Raji (human B } \\
\text { lymphoma) cell lines }\end{array}$ & Cytotoxicity & {$[123]$} \\
\hline Melissa officinalis & Human breast cancer (MCF-7) cell lines & Cytotoxicity & {$[124]$} \\
\hline Satureja intermedia & $\begin{array}{l}\text { Human oesophagus squamous cell (KYSE30) } \\
\text { and bladder carcinoma (5637) cell lines }\end{array}$ & Cytotoxicity & {$[125]$} \\
\hline Origanum majorana & H1299 and epirubicin-resistant H1299 cell lines & $\begin{array}{l}\text { Cytotoxic and induces } \\
\text { DNA damage }\end{array}$ & {$[101]$} \\
\hline
\end{tabular}


TABLe 2: Continued.

\begin{tabular}{|c|c|c|c|}
\hline EO bearing plants & Model system & $\begin{array}{l}\text { Major } \\
\text { findings/mechanism(s) } \\
\text { reported }\end{array}$ & Reference \\
\hline Guatteria pogonopus & $\begin{array}{l}\text { Ovarian adenocarcinoma (OVCAR-8), } \\
\text { bronchoalveolar lung carcinoma (NCIH358M), } \\
\text { and metastatic prostate carcinoma (PC-3M) } \\
\text { cell lines }\end{array}$ & Cytotoxic & [126] \\
\hline Pyrolae herba & Human chondrosarcoma (SW1353) cells & Antitumour activity & {$[66]$} \\
\hline Thymus revolutus & Liver cancer (HepG2) cells & $\begin{array}{l}\text { Prooxidant and protective } \\
\text { effects }\end{array}$ & [127] \\
\hline Origanum onites $\mathrm{L}$. & $\begin{array}{l}\text { 5RP7 (c-H-ras transformed rat embryonic } \\
\text { fibroblasts) cell lines }\end{array}$ & Apoptosis & [128] \\
\hline Capparis spinosa $\mathrm{L}$. & Human colon carcinoma (HT-29) cell line & $\begin{array}{l}\text { Inhibition of cell } \\
\text { proliferation via } G_{2} / M \text { cell } \\
\text { cycle arrest }\end{array}$ & {$[129]$} \\
\hline Artemisia campestris and Thymelaea hirsuta & Colon cancer (HT-29) cells & Antitumour activity & {$[27]$} \\
\hline Lycopus lucidus Turcz. var. hirtus Regel & $\begin{array}{l}\text { Human liver (Bel-7402 and HepG2), breast } \\
\text { (MDA-MB-435S and ZR-75-30), cervix (HeLa) } \\
\text { and human renal adenocarcinoma (ACHN) } \\
\text { cell lines }\end{array}$ & Cytotoxicity & {$[10]$} \\
\hline Nigella sativa & Human epithelial (Hep-2) cell lines & Cytotoxicity & {$[130]$} \\
\hline Thymus vulgaris & $\begin{array}{l}\text { Oral cavity squamous cell carcinoma (OCSCC) } \\
\text { cells }\end{array}$ & Cytotoxicity & [131] \\
\hline Aniba rosaeodora & $\begin{array}{l}\text { Human epidermoid carcinoma cells (A431), } \\
\text { epidermal keratinocytes (HEK001), normal } \\
\text { primary epidermal keratinocytes (NHEK) and } \\
\text { HaCaT cell lines }\end{array}$ & $\begin{array}{l}\text { Apoptosis induction in } \\
\text { selective manner }\end{array}$ & {$[51]$} \\
\hline Boswellia sacra & $\begin{array}{l}\text { Human breast cancer (T47D, MCF7, } \\
\text { MDA-MB-231) and immortalized normal } \\
\text { human breast (MCF10-2A) cell line }\end{array}$ & $\begin{array}{l}\text { Cytotoxic to cancer cells } \\
\text { but not to normal cells }\end{array}$ & {$[50]$} \\
\hline Syzygium aromaticum $L$ & $\begin{array}{l}\text { Breast cancer (MCF-7 and MDA-MB-231), } \\
\text { prostate cancer (DU-145), cervical cancer } \\
\text { (HeLa), and Esophageal cancer (TE-13) cell } \\
\text { lines }\end{array}$ & Cytotoxicity & {$[132]$} \\
\hline Murraya koenigii & MCF-7, P 388, and HeLa cell lines & Antitumour activity & {$[133]$} \\
\hline Salvia officinalis & $\begin{array}{l}\text { Breast cancer (MCF-7) and colon cancer } \\
\text { (HCT-116) cell lines }\end{array}$ & Cytotoxicity & {$[134]$} \\
\hline $\begin{array}{l}\text { Mentha spicata L., Zingiber officinale, } \\
\text { Citrus limon Burm. f., C. paradise Macf., } \\
\text { Jasminum grandiflora, lavender, } \\
\text { Matricaria chamomilla, Thymus vulgaris, } \\
\text { Rosa damascena, and cinnamon }\end{array}$ & $\begin{array}{l}\text { Human prostate carcinoma (PC-3), lung } \\
\text { carcinoma (A549), and breast cancer (MCF-7) } \\
\text { cell lines }\end{array}$ & Cytotoxicity & {$[28]$} \\
\hline Artemisia lavandulaefolia & Human oral epidermoid carcinoma (KB) cells & $\begin{array}{l}\text { Mitochondrial stress and } \\
\text { caspase activation mediated } \\
\text { apoptosis }\end{array}$ & {$[23]$} \\
\hline $\begin{array}{l}\text { Laurus nobilis, Origanum syriacum, } \\
\text { Origanum vulgare, and Salvia triloba }\end{array}$ & Human breast (MCF7) adenocarcinoma cells & Cytotoxicity & [135] \\
\hline $\begin{array}{l}\text { Schinusmolle L. and Schinus terebinthifolius } \\
\text { Raddi }\end{array}$ & Human breast (MCF-7) cancer cells & Cytotoxicity & [136] \\
\hline Ocimum viride & $\begin{array}{l}\text { Human colorectal adenocarcinoma (COLO } \\
\text { 205) cell line }\end{array}$ & $\begin{array}{l}\text { Time and dose-dependent } \\
\text { cytotoxicity }\end{array}$ & {$[137]$} \\
\hline Cinnamomum zeylanicum & $\begin{array}{l}\text { Normal rat embryonic fibroblasts (F2408) and } \\
\text { c-H-ras transformed rat embryonic fibroblasts } \\
\text { (5RP7) cell lines }\end{array}$ & Cytotoxicity and apoptosis & [138] \\
\hline $\begin{array}{l}\text { Citrus reticulate, C. aurantium, C. } \\
\text { limon, and C. aurantium }\end{array}$ & $\begin{array}{l}\text { Ehrlich ascites carcinoma resistant to Endoxan } \\
\text { cells }\end{array}$ & Antitumour activity & [139] \\
\hline
\end{tabular}


TABLe 2: Continued.

\begin{tabular}{|c|c|c|c|}
\hline EO bearing plants & Model system & $\begin{array}{l}\text { Major } \\
\text { findings/mechanism(s) } \\
\text { reported }\end{array}$ & Reference \\
\hline Morus rotunbiloba Koidz & $\begin{array}{l}\text { African green monkey kidney (Vero) and } \\
\text { human larynx epidermoid carcinoma (Hep2) } \\
\text { and colon adenocarcinoma (SW620) cell lines }\end{array}$ & Cytotoxicity & {$[140]$} \\
\hline Amomum tsaoko & $\begin{array}{l}\text { Human liver carcinoma (HepG2 and Bel-7402), } \\
\text { cervix carcinoma (HeLa), lung carcinoma } \\
\text { (A549), gastric adenocarcinoma (SGC-7901), } \\
\text { prostate cancer (PC-3), hepatocyte (HL-7702), } \\
\text { and umbilical vein endothelial (HUVEC) cell } \\
\text { lines }\end{array}$ & $\begin{array}{l}\text { Cytotoxicity to cancer cells } \\
\text { but lesser effect on normal } \\
\text { cell line }\end{array}$ & {$[141]$} \\
\hline Salvia pisidica & Hepatoma G2 (HepG2) and H1299 cell lines & $\begin{array}{l}\text { Protective effect against } \\
\mathrm{H}_{2} \mathrm{O}_{2} \text { induced toxicity }\end{array}$ & {$[15]$} \\
\hline Citrus limon & Human cervical adenocarcinoma (HeLa) cells & Antiproliferative activity & [142] \\
\hline Rosmarinus officinalis & $\begin{array}{l}\text { Human breast cancer (MCF-7) and hormone } \\
\text { dependent prostate carcinoma (LNCaP) cell } \\
\text { lines }\end{array}$ & Antiproliferative activity & {$[143]$} \\
\hline Hibiscus cannabinus & $\begin{array}{l}\text { Ovarian cancer (CaOV3) and colon cancer } \\
\text { (HT29) cell lines }\end{array}$ & Cytotoxicity and apoptosis & {$[144]$} \\
\hline Salvia rubifolia and S. bracteata & Human melanoma (M14) cells & Cytotoxicity & [45] \\
\hline Croton regelianus & $\begin{array}{l}\text { Human leukemia (HL-60), melanoma } \\
\text { (MDA-MB-435), brain (SF-295), and colon } \\
\text { (HCT-8) cell lines }\end{array}$ & Cytotoxicity & {$[145]$} \\
\hline Citrus aurantifolia & $\begin{array}{l}\text { Colon adenocarcinoma (NIH3T3 and SW-480) } \\
\text { cells }\end{array}$ & $\begin{array}{l}\text { Apoptosis induction by } \\
\text { DNA fragmentation and } \\
\text { caspase- } 3 \text { elevation }\end{array}$ & [146] \\
\hline $\begin{array}{l}\text { Stachys cretica ssp. vacillans Rech. Fil., S. } \\
\text { germanica L., S. hydrophila Boiss., S. } \\
\text { nivea, S. palustris. and S. spinosa, }\end{array}$ & $\begin{array}{l}\text { Amelanotic melanoma }(\mathrm{C} 32) \text { and renal cell } \\
\text { adenocarcinoma }(\mathrm{ACHN}) \text { cell lines }\end{array}$ & Antiproliferative activity & {$[147]$} \\
\hline $\begin{array}{l}\text { Cnidium officinale and } \\
\text { Ligusticum chuanxion }\end{array}$ & Mouse skin fibroblast (NIH 3T3) cells & $\begin{array}{l}\text { Preventive effect against } \\
\text { UVB-induced DNA } \\
\text { damage and apoptosis }\end{array}$ & {$[65]$} \\
\hline Schefflera heptaphylla & $\begin{array}{l}\text { Breast cancer (MCF-7), melanoma (A375), and } \\
\text { liver cancer (HepG2) cell lines }\end{array}$ & Anti-proliferative activity & [148] \\
\hline Lippia alba & $\begin{array}{l}\text { Human cervix epithelioid carcinoma cells } \\
\text { (HeLa) and African green monkey kidney } \\
\text { (Vero) cell lines }\end{array}$ & $\begin{array}{l}\text { Cytotoxic to HeLa but not } \\
\text { to nontumorigenic Vero }\end{array}$ & [149] \\
\hline Piper gaudichaudianum & $\begin{array}{l}\text { Chinese hamster lung fibroblast (V79 cells) } \\
\text { cells }\end{array}$ & Cytotoxicity & {$[150]$} \\
\hline Citrus reticulate and Pelargonium graveolens & $\begin{array}{l}\text { Human promyelocytic leukemia (HL-60 and } \\
\text { NB4) cell lines }\end{array}$ & Antiproliferative activity & {$[151]$} \\
\hline Boswellia sp. & $\begin{array}{l}\text { Bladder transitional cell carcinoma (J82) and } \\
\text { normal human urothelium primary (UROtsa) } \\
\text { cell lines }\end{array}$ & $\begin{array}{l}\text { Cytotoxic to carcinoma but } \\
\text { not normal cell line }\end{array}$ & {$[46]$} \\
\hline Salvia libanotica & $\begin{array}{l}\text { Isogenic colon cancer }(\mathrm{HCT}-116 \mathrm{p} 53+/+ \text { and } \\
\text { p53-/-) cell lines }\end{array}$ & Inhibitory activity & {$[48]$} \\
\hline Cinnamomum osmophloeum & $\begin{array}{l}\text { Murine macrophage (RAW 264.7) and human } \\
\text { hepatocellular liver carcinoma (HepG2) cell } \\
\text { lines }\end{array}$ & Cytotoxicity & [152] \\
\hline $\begin{array}{l}\text { Eucalyptus sideroxylon and } \\
\text { Eucalyptus torquata }\end{array}$ & $\begin{array}{l}\text { Human hepatocellular carcinoma (HepG2) and } \\
\text { breast adenocarcinoma (MCF7) cell lines }\end{array}$ & Antiproliferative activity & {$[153]$} \\
\hline Schinus molle & $\begin{array}{l}\text { Mouse macrophage (774), mouse breast } \\
\text { carcinoma (EMT6), mouse myoblast (C2C12) } \\
\text { and human hepatoma (Hep3B and HepG2), } \\
\text { bladder Carcinoma (ECV-304), and leukemic } \\
\text { (K562) cell lines }\end{array}$ & Cytotoxicity & [154] \\
\hline
\end{tabular}


TABle 2: Continued.

\begin{tabular}{|c|c|c|c|}
\hline EO bearing plants & Model system & $\begin{array}{l}\text { Major } \\
\text { findings/mechanism(s) } \\
\text { reported }\end{array}$ & Reference \\
\hline Casearia sylvestris & $\begin{array}{l}\text { Human cervical carcinoma (HeLa), lung } \\
\text { carcinoma (A549), colon adenocarcinoma } \\
\text { (HT-29), monkey kidney (Vero) cell lines, and } \\
\text { mice macrophages }\end{array}$ & $\begin{array}{l}\text { Antitumour but less } \\
\text { cytotoxic against Vero and } \\
\text { Macrophages }\end{array}$ & {$[37]$} \\
\hline Curcuma wenyujin & Human hepatoma (HepG2) cell line & $\begin{array}{l}\text { Ant-proliferative activity by } \\
\text { induction of apoptosis }\end{array}$ & {$[68]$} \\
\hline Dictamnus dasycarpus & $\begin{array}{l}\text { Human breast cancer (MCF-7, ZR-75-30 and } \\
\text { MDA-MB-435S), liver carcinoma (Bel-7402 } \\
\text { and HepG2), and renal adenocarcinoma } \\
\text { (ACHN) cell lines }\end{array}$ & $\begin{array}{l}\text { Antiproliferative activity } \\
\text { with more sensitivity } \\
\text { towards breast cancer cells }\end{array}$ & {$[155]$} \\
\hline $\begin{array}{l}\text { Salvia officinalis, Sideritis perfoliata, } \\
\text { Satureja thymbra, Laurus nobilis, and } \\
\text { Pistacia palaestina }\end{array}$ & $\begin{array}{l}\text { Breast cancer (MCF-7), amelanotic melanoma } \\
\text { (C32), renal cell adenocarcinoma (ACHN), and } \\
\text { hormone dependent prostrate carcinoma } \\
\text { (LNCaP) cell lines }\end{array}$ & Cytotoxic & {$[156]$} \\
\hline Juniperus phoenicea & $\begin{array}{l}\text { Brain tumour (U251), lung carcinoma cell line } \\
\text { (H460), liver carcinoma cell line (HepG2), } \\
\text { breast carcinoma cell line (MCF-7), and cervix } \\
\text { carcinoma (HeLa) }\end{array}$ & Cytotoxic effects & {$[157]$} \\
\hline Zanthoxylum rhoifolium Lam & $\begin{array}{l}\text { Human cervical carcinoma (HeLa), lung } \\
\text { carcinoma (A549), colon adenocarcinoma } \\
\text { (HT-29), monkey kidney (Vero), and mice } \\
\text { macrophages cell lines }\end{array}$ & $\begin{array}{l}\text { Cytotoxic to cancer cells } \\
\text { but not cytotoxic to Vero } \\
\text { and Macrophage cells }\end{array}$ & [158] \\
\hline Thymus broussonetii & $\begin{array}{l}\text { Human ovarian adenocarcinoma IGR-OV1 } \\
\text { parental OV1/P and its chemoresistant } \\
\text { OV1/adriamycin (OV1/ADR), OV1/vincristine } \\
\text { (OV1/VCR), and OV1/cisplatin (OV1/CDDP) } \\
\text { cell lines }\end{array}$ & $\begin{array}{l}\text { Antitumour in the cancer } \\
\text { cells resistant to } \\
\text { chemotherapy }\end{array}$ & {$[96]$} \\
\hline Photinia serrulata & $\begin{array}{l}\text { Human cervical carcinoma (HeLa), lung } \\
\text { carcinoma (A-549), and liver carcinoma } \\
\text { (Bel-7402) cell lines }\end{array}$ & Anticancer activity & [159] \\
\hline Thymus sp. & Mastocytoma (P815) cell line & $\begin{array}{l}\text { Inhibitory effect with } \\
\text { carvacrol showing most } \\
\text { cytotoxic }\end{array}$ & {$[88]$} \\
\hline Neem oil & Human (MCF-7) breast cancer cell lines & $\begin{array}{l}\text { Slow, nonapoptotic cell } \\
\text { death }\end{array}$ & {$[160]$} \\
\hline $\begin{array}{l}\text { Talauma ovata, Symphyopappus itatiayensis, } \\
\text { Myrciaria floribunda, Psidium cattleianum, } \\
\text { and Nectandra megapotamica }\end{array}$ & $\begin{array}{l}\text { Breast adenocarcinoma (MCF-7), colon } \\
\text { adenocarcinoma (KM-12), multiple myeloma } \\
\text { (RPMI-8226), prostate carcinoma (PC-3), } \\
\text { glioblastoma (SF-268), and lung carcinoma } \\
\text { (NCI-H460) cell lines }\end{array}$ & Cytotoxicity & {$[161]$} \\
\hline $\begin{array}{l}\text { O. sanctum, C. citratus, Alpiniaofficinarum, } \\
\text { L. angustifolia, Vetiveria zizanioides, } Z \text {. } \\
\text { montanum, P. nigrum, C. nardus, C. } \\
\text { longa, O. basilicum, C. hystrix, } P . \\
\text { betel, Albizia lebbeck, O. americanum, } M . \\
\text { spicata, and Psidium guajava }\end{array}$ & $\begin{array}{l}\text { Human mouth epidermal carcinoma (KB) and } \\
\text { murine leukemia (P388) cell lines }\end{array}$ & Antiproliferative activity & {$[162]$} \\
\hline Pistacia lentiscus var. chia & K562 and B16 cells & $\begin{array}{l}\text { Inhibition of growth, } \\
\text { survival, and angiogenesis }\end{array}$ & {$[163]$} \\
\hline Citrus limon, C. medica, C. sinsensis & $\begin{array}{l}\text { Human cervix carcinoma (Hela) and breast } \\
\text { adenocarcinoma (MCF-7) cell lines }\end{array}$ & Cytotoxicity & {$[164]$} \\
\hline Eugenia caryophyllata & $\begin{array}{l}\text { Human promyelocytic leukemia cells (HL-60), } \\
\text { histiocytic lymphoma (U-937), hepatoma } \\
\text { (HepG2), human colon cancer (SNU-C5), and } \\
\text { Lewis mouse lung carcinoma (3LL) }\end{array}$ & ROS mediated apoptosis & {$[165]$} \\
\hline Zanthoxylum schinifolium & Human Hepatoma Cells (HepG2) & $\begin{array}{l}\text { Apoptosis induction via } \\
\text { ROS }\end{array}$ & {$[52]$} \\
\hline
\end{tabular}


TABLe 2: Continued.

\begin{tabular}{|c|c|c|c|}
\hline EO bearing plants & Model system & $\begin{array}{l}\text { Major } \\
\text { findings/mechanism(s) } \\
\text { reported }\end{array}$ & Reference \\
\hline Myrica gale & $\begin{array}{l}\text { Human lung carcinoma (A549) and colon } \\
\text { adenocarcinoma (DLD-1) }\end{array}$ & Cytotoxicity & {$[166]$} \\
\hline Abies balsamea & $\begin{array}{l}\text { MCF-7, PC-3, A549, DLD-1, M4BEU, and } \\
\text { CT-26 }\end{array}$ & $\begin{array}{l}\text { Antitumour activity } \\
\text { induced by ROS }\end{array}$ & {$[167]$} \\
\hline Lavandula stoechas ssp. stoechas & $\begin{array}{l}\text { Human epidermoid carcinoma (KB), human } \\
\text { breast cancer (BC1), lung cancer (LU1), colon } \\
\text { cancer (COL-2), drug-resistant KB (KB-V), } \\
\text { mouse leukemia (P-388), hormone-dependent } \\
\text { human prostate cancer (LNCaP), and rat } \\
\text { glioma (ASK) cell lines }\end{array}$ & $\begin{array}{l}\text { Variable cytotoxicity to all } \\
\text { except ASK cell line }\end{array}$ & {$[168]$} \\
\hline
\end{tabular}

TABLE 3: List of EO bearing plants studied for anticancer potential in in vivo models and major observations reported.

\begin{tabular}{|c|c|c|c|}
\hline EO bearing plants & In vivo models studied & $\begin{array}{l}\text { Major } \\
\text { findings/mechanism(s) } \\
\text { reported }\end{array}$ & Reference \\
\hline Pomegranate & Skin tumour in CD1 Mice & Chemopreventive effect & {$[84]$} \\
\hline $\begin{array}{l}\text { Cymbopogon citrates } \\
\text { STAPF }\end{array}$ & Female Balb/C mice & Anticarcinogenic activity & {$[169]$} \\
\hline Croton regelianus & Sarcoma 180 murine model & Antitumour activity & {$[145]$} \\
\hline Salvia libanotica & Mice & $\begin{array}{l}\text { Chemoprevention against } \\
\text { skin papillomas }\end{array}$ & {$[83]$} \\
\hline Xylopia frutescens & $\begin{array}{l}\text { Sarcoma } 180 \text { ascites tumour } \\
\text { cells injected in mice }\end{array}$ & Tumour growth inhibition & {$[120]$} \\
\hline Thymus broussonetii & $\begin{array}{l}\text { DBA-2/P815 (H2d) mouse } \\
\text { model }\end{array}$ & $\begin{array}{l}\text { Tumour reduction by } \\
\text { injection of the EO }\end{array}$ & {$[96]$} \\
\hline Plectranthus amboinicus & $\begin{array}{l}\text { B16F-10 melanoma cell line } \\
\text { injected C57BL/6 mice }\end{array}$ & $\begin{array}{l}\text { Prevention of lung } \\
\text { metastasis }\end{array}$ & {$[170]$} \\
\hline Lippia gracilis & Sarcoma 180 bearing mice & Tumour growth inhibition & {$[22]$} \\
\hline Guatteria pogonopus & $\begin{array}{l}\text { Sarcoma } 180 \text { tumour } \\
\text { bearing Swiss mice }\end{array}$ & Tumour inhibition & {$[126]$} \\
\hline Neem & RIII/Sa female mice & Tumour reduction & {$[160]$} \\
\hline Curcuma zedoaria & Mice & Angiogenesis inhibition & {$[171]$} \\
\hline $\begin{array}{l}\alpha \text {-Pinene from } \\
\text { Schinus terebinthifolius } \\
\text { Raddi }\end{array}$ & $\begin{array}{l}\text { C57Bl/6 mice with } \\
\text { B16F10-Nex2 induced } \\
\text { melanoma }\end{array}$ & Antimetastasis & {$[77]$} \\
\hline
\end{tabular}

level. Yu et al., using Bel-7402 cell line, had reported that the glutathione level in the body regulates cell proliferation [10]. A study on human melanoma cells reported that treatment of EOs induces DNA damage in cancer cells which is an indicator of apoptosis [45]. Apart from DNA damage, modification of various genes by the action of EOs is also responsible for apoptosis. Frank et al. studied the action of Boswellia carteri EO (frankincense oil) in bladder cancer cells and observed modulation of CDKN1A, DEDD2, IER3, IL6, SGK, TNFAIP3 GAD45B, and NUDT2 genes involved in apoptosis [46].

EOs were also demonstrated to change expression levels of Bcl-2 and Bax genes leading to release of cytochrome C into cytosol in KB human oral epidermoid carcinoma cells [23].
This happens via activation of caspase-9 leading to caspase3 formation which in turn cleaves target that causes apoptosis and increased phosphorylation of extracellular signalregulated kinase (ERK), c-jun $\mathrm{N}$-terminal kinase, and p38 MAPK [23]. EO-induced apoptosis has been also suggested to be involving mitochondrial and MAPKs pathways [23]. Antiapoptotic $\mathrm{Bcl}-2$ protein is downregulated by the action of EOs on the cancer cells [47]. In mouth cancer KB cells, Artemisia lavandulaefolia $\mathrm{EO}$ has been shown to decrease $\mathrm{Bcl}-2$ protein level in dose dependent manner [23], which leads to apoptosis in cancer cells that is an important strategy to control cancer development and progression.

EO constituents lead to poly(ADP-ribose) polymerase-1 (PARP) cleavage [48] which is an indicator of apoptosis [49]. 
TABLE 4: List of EO constituents studied for anticancer potential in both in vitro and in vivo models, and major observations reported.

\begin{tabular}{|c|c|c|c|}
\hline Constituents used & Model systems used & Major findings/mechanism(s) reported & Reference \\
\hline $\begin{array}{l}\text { Azadirachtin and } \\
\text { nimbolide }\end{array}$ & $\begin{array}{l}\text { Hamster buccal pouch (HBP) } \\
\text { carcinogenesis model }\end{array}$ & $\begin{array}{l}\text { Cell cycle arrest and apoptosis by intrinsic and extrinsic } \\
\text { pathway }\end{array}$ & {$[172]$} \\
\hline $\begin{array}{l}\text { Azadirachtin and } \\
\text { nimbolide }\end{array}$ & Hepatocarcinoma (HepG2) & $\begin{array}{l}\mathrm{G}_{0} / \mathrm{G}_{1} \text { phase cell cycle and apoptosis via ROS induction } \\
\text { and cytochrome } \mathrm{C} \text { release in mitochondria }\end{array}$ & {$[173]$} \\
\hline $\begin{array}{l}\text { Azadirachtin and } \\
\text { nimbolide }\end{array}$ & $\begin{array}{l}\text { Hamster buccal pouch (HBP) } \\
\text { carcinogenesis model }\end{array}$ & $\begin{array}{l}\text { Chemoprevention of 7,12-dimethylbenz[a]anthracene } \\
\text { (DMBA)-induced cancer, prevention of procarcinogen } \\
\text { activation and oxidative DNA damage, upregulation of } \\
\text { antioxidant and carcinogen detoxification enzymes, } \\
\text { inhibition of tumour invasion and angiogenesis }\end{array}$ & {$[174]$} \\
\hline Carvacrol & $\begin{array}{l}\text { Male wistar albino rats with liver } \\
\text { cancer induced by diethylnitrosamine } \\
\text { (DEN) }\end{array}$ & Chemoprevention & {$[29]$} \\
\hline Carvacrol & $\begin{array}{l}\text { Human cervical cancer cell lines } \\
\text { (HeLa and } \mathrm{SiHa})\end{array}$ & Apoptosis & {$[175]$} \\
\hline Carvacrol & $\begin{array}{l}\text { K-562, P-815, CEM, MCF-7 and } \\
\text { MCF-7 gem (gemcitabine resistant) }\end{array}$ & Arrest in S-phase progression & {$[39]$} \\
\hline Carvacrol & Liver cancer (HepG2) cell line & $\begin{array}{l}\text { Apoptosis via activation of caspases and } \\
\text { mitogen-activated protein kinase (MAPK) pathway }\end{array}$ & {$[176]$} \\
\hline Carvacrol & Lung cancer (A549) cell line & Growth inhibition & {$[177]$} \\
\hline Carvacrol & $\begin{array}{l}\text { Human metastatic breast cancer } \\
\text { (MDA-MB 231) cell line }\end{array}$ & Apoptosis & {$[178]$} \\
\hline Carvone & $\begin{array}{l}\text { Primary rat neuron and } \\
\text { neuroblastoma (N2a) cells }\end{array}$ & $\begin{array}{l}\text { Increase in antioxidant level in primary cells with little } \\
\text { potential in treatment of brain tumour }\end{array}$ & {$[179]$} \\
\hline Citral & Breast cancer (MCF-7) cell line & $\mathrm{G}_{2} / \mathrm{M}$ phase arrest and apoptosis & {$[41]$} \\
\hline $\begin{array}{l}\text { Citronellal and } \\
\text { synthetic analog } \\
\text { C37A } \\
\text { (N-citronellylamine) }\end{array}$ & $\begin{array}{l}\text { Human breast cancer (MCF-7) and a } \\
\text { non-tumorigenic (Vero) cell line }\end{array}$ & Cytotoxicity & {$[114]$} \\
\hline D-limonene & Colon cancer (LS174T) cells & Apoptosis by inactivation of akt pathway & [180] \\
\hline Elemene & Laryngeal cancer (Hep-2) cells & $\begin{array}{l}\text { Growth inhibition via decrease in eIF4E, eIF4G, bFGF } \\
\text { and VEGF }\end{array}$ & {$[181]$} \\
\hline Elemene & Colon cancer (Lovo) cells & $\begin{array}{l}\text { Inhibition of telomerase activity, cell cycle arrest, and } \\
\text { apoptosis }\end{array}$ & {$[182]$} \\
\hline Eugenol & $\begin{array}{l}\text { Primary melanoma (Sbcl2), radial } \\
\text { growth phase (WM3211), primary } \\
\text { RGP, radial and vertical growth phase } \\
\text { (WM98-1), primary RGP and VGP, } \\
\text { Lu-metastatic melanoma (WM1205) } \\
\text { and Female B6D2F1 mice with B16 } \\
\text { melanomas }\end{array}$ & $\begin{array}{l}\text { Suppresses melanoma via deregulation of the E2F1 } \\
\text { transcription factors }\end{array}$ & {$[183]$} \\
\hline Eugenol & $\begin{array}{l}\mathrm{N} \text {-methyl- } \mathrm{N}^{\prime} \text {-nitro-N- } \\
\text { nitrosoguanidine (MNNG) induced } \\
\text { gastric cancer in rat }\end{array}$ & Tumour reduction by suppression of NF- $\kappa \mathrm{B}$ activation & {$[184]$} \\
\hline Eugenol & Breast cancer (MCF-7) cells & $\begin{array}{l}\text { Growth inhibition and apoptosis induction with } \\
\text { decrease in levels of intracellular antioxidants }\end{array}$ & {$[184]$} \\
\hline Eugenol & $\begin{array}{l}\text { Androgen-insensitive prostate cancer } \\
\text { cells (DU-145) and oral squamous } \\
\text { carcinoma (KB) cells }\end{array}$ & $\begin{array}{l}\text { Eugenol and its synthetic analogues inhibited growth } \\
\text { without losing membrane integrity }\end{array}$ & {$[185]$} \\
\hline Eugenol & Human colon cancer (HT-29) cells & Suppression of cyclooxygenase-2 activity and growth & {$[186]$} \\
\hline Eugenol & $\begin{array}{l}\text { Colon cancer (HCT-15 and HT-29) } \\
\text { cells }\end{array}$ & Induction of ROS leading to apoptosis & [187] \\
\hline Eugenol & $\begin{array}{l}\text { Human promyelocytic leukemia } \\
\text { (HL-60) cells }\end{array}$ & $\begin{array}{l}\text { Induction of ROS, mitochondrial permeability } \\
\text { transition (MPT), reduction of bcl-2 level, cytochrome } \\
\mathrm{c} \text { release leading to apoptosis }\end{array}$ & {$[165]$} \\
\hline
\end{tabular}


TABle 4: Continued.

\begin{tabular}{|c|c|c|c|}
\hline Constituents used & Model systems used & Major findings/mechanism(s) reported & Reference \\
\hline Eugenol & Human Melanoma (G361) cell line & S-phase cell cycle arrest and apoptosis & [188] \\
\hline Furanodiene & Liver cancer (HepG2) cell line & $\begin{array}{l}\mathrm{G}_{2} / \mathrm{M} \text { phase arrest and apoptosis via inhibition of } \\
\text { MAPK signalling pathway }\end{array}$ & [189] \\
\hline Geraniol & Human colon cancer (Caco) cell line & Enhances sensitivity to 5-fluorouracil treatment & {$[32]$} \\
\hline Geraniol & Human colon cancer (Caco) cell line & $\begin{array}{l}\text { Inhibits growth and Polyamine } \\
\text { biosynthesis-mechanism of inhibition of proliferation }\end{array}$ & {$[31]$} \\
\hline Geraniol & Human colon cancer (Caco) cell line & $\begin{array}{l}\text { Membrane depolarisation, decreased activity of protein } \\
\text { kinase } \mathrm{C} \text { activity and } \mathrm{p} 44 / \mathrm{p} 42 \text { extracellular } \\
\text { signal-regulated protein kinases (ERK) }\end{array}$ & {$[190]$} \\
\hline Geraniol & $\begin{array}{l}\text { Human tumours (TC-118) induced in } \\
\text { Swiss nu/nu mice }\end{array}$ & $\begin{array}{l}\text { Reduction in thymidylate synthase and thymidine } \\
\text { kinase expression, synergistic effect of geraniol with } \\
\text { 5-fluorouracil }\end{array}$ & [33] \\
\hline Germacrene D & $\begin{array}{l}\text { Murine melanoma (B16F10-Nex2), } \\
\text { human glioblastoma (U-87 MG), } \\
\text { cervical carcinoma (HeLa), leukemia } \\
\text { (HL-60), colon carcinoma (HCT), } \\
\text { breast adenocarcinoma (SKBr), and } \\
\text { melanoma (A2058); and } \\
\text { non-tumorigenic (HFF) cell lines }\end{array}$ & Cytotoxicity & {$[116]$} \\
\hline Neem oil limonoids & $\begin{array}{l}\text { Colon cancer (HCT116 p53-/-, } \\
\text { HCT116 p21-/-) LNCaP, PPC1 and } \\
\text { MDA-MB231 cell lines }\end{array}$ & p53 independent apoptosis autophagy & {$[191]$} \\
\hline Nimbolide & $\begin{array}{l}\text { Colorectal cancer (CRC) cell lines and } \\
\text { CRC xenografts in nude mouse model }\end{array}$ & $\begin{array}{l}\text { Apoptosis by caspase activation and PARP cleavage and } \\
\text { decrease in tumour size in xenograft models }\end{array}$ & [192] \\
\hline Nimbolide & Human hepatocarcinoma (HepG2) & $\begin{array}{l}\text { Bcl-2, Bax, cytochrome- } c \text {, Smac/DIABLO, caspase- } 3 \text {, } \\
\text { and caspase- } 9 \text { activation leading to intrinsic pathway } \\
\text { for apoptosis NF- } \kappa \text { B signaling }\end{array}$ & {$[193]$} \\
\hline Nimbolide & Colon cancer (WiDr) cells & $\begin{array}{l}\text { S-phase cell cycle arrest and caspase-mediated } \\
\text { apoptosis }\end{array}$ & {$[194]$} \\
\hline Patchouli alcohol & $\begin{array}{l}\text { Human colorectal cancer (HCT 116, } \\
\text { SW480) cells }\end{array}$ & $\begin{array}{l}\text { NF- } \kappa \mathrm{B}, \mathrm{p} 21 \text { activation and suppression of cyclin D1 and } \\
\text { cyclin-dependent kinase } 4 \text { (CDK4) resulting in } \\
\text { apoptosis and decreased growth }\end{array}$ & {$[65]$} \\
\hline Perillyl alcohol & $\begin{array}{l}\text { Human colon carcinoma (HCT 116) } \\
\text { cell line }\end{array}$ & Dose dependent inhibition attributed to $G_{1}$ arrest & {$[70]$} \\
\hline Perillyl alcohol & Female BALB/c mice & Tumour inhibition & {$[195]$} \\
\hline Perillyl alcohol & $\mathrm{BALB} / \mathrm{c}$ mice & $\begin{array}{l}\text { UV-B induced AP- } 1 \text { trans-activation inhibition and } \\
\text { reduction of the tumours }\end{array}$ & {$[60]$} \\
\hline Perillyl alcohol & $\begin{array}{l}\text { Lung cancer (A549 and H520) cell } \\
\text { lines }\end{array}$ & Cell cycle arrest and apoptosis & [196] \\
\hline Terpinen-4-ol & $\begin{array}{l}\text { Murine mesothelioma (AE17), } \\
\text { melanoma cells (B16-F10), and } \\
\text { fibroblasts (L929) }\end{array}$ & $\begin{array}{l}\text { Necrotic cell death and apoptosis to lower extent in } \\
\text { cancer cells }\end{array}$ & [197] \\
\hline Thymol & $\begin{array}{l}\text { Human promyelocytic leukemia } \\
\text { (HL-60) cells }\end{array}$ & Caspase-dependent and independent apoptosis & {$[40]$} \\
\hline Thymol & Human liver cancer (Bel-7402) cells & Antiproliferative activity & [198] \\
\hline Thymol & $\begin{array}{l}\text { K-562, P-815, CEM, MCF-7, and } \\
\text { MCF-7 gem }\end{array}$ & Prevention of $\mathrm{G}_{0} / \mathrm{G}_{1}$ phase transition & {$[39]$} \\
\hline Thymoquinone & $\begin{array}{l}\text { Human colon cancer (LoVo, HCT 116, } \\
\text { Caco-2, HT-29 and DLD-1) and } \\
\text { human intestinal (FHs74Int) cells }\end{array}$ & $\begin{array}{l}\text { ROS generation and mitogen-activated protein kinases } \\
\text { (MAPK) JNK and ERK activation in cancer cells } \\
\text { leading to apoptosis }\end{array}$ & [199] \\
\hline Trans-caryophyllene & $\begin{array}{l}\text { Breast cancer (MCF-7), colon cancer } \\
\text { (HCT-116) and murine macrophage } \\
\text { (RAW264.7) cell lines }\end{array}$ & Cytotoxicity & {$[134]$} \\
\hline
\end{tabular}


TABLE 4: Continued.

\begin{tabular}{|c|c|c|c|}
\hline Constituents used & Model systems used & Major findings/mechanism(s) reported & Reference \\
\hline$\alpha$-humulene & $\begin{array}{l}\text { Breast cancer (MCF-7), colon cancer } \\
\text { (HCT-116) and murine macrophage } \\
\text { (RAW264.7) cell lines }\end{array}$ & Cytotoxicity & {$[134]$} \\
\hline$\alpha$-santalol & $\begin{array}{l}\text { Breast cancer (MCF-7 and } \\
\text { MDA-MB-231) cells }\end{array}$ & $\begin{array}{l}\mathrm{G}_{2} / \mathrm{M} \text { phase cell cycle arrest and apoptosis with little } \\
\text { effect on normal breast cells }\end{array}$ & {$[200]$} \\
\hline$\beta$-caryophyllene & $\begin{array}{l}\text { Human tumour (MCF-7, DLD-1 and } \\
\text { L-929) cell lines }\end{array}$ & $\begin{array}{l}\text { Enhanced activity of } \alpha \text {-humulene, isocaryophyllene, } \\
\text { and paclitaxel }\end{array}$ & {$[38]$} \\
\hline $\begin{array}{l}\beta \text {-Caryophyllene } \\
\text { oxide }\end{array}$ & $\begin{array}{l}\text { Human prostate (PC-3) and breast } \\
\text { cancer (MCF-7) cells }\end{array}$ & $\begin{array}{l}\text { ROS generation and PI3K/AKT/mTOR/S6K1 signaling } \\
\text { activation leading to apoptosis }\end{array}$ & [201] \\
\hline$\beta$-elemene & Lung cancer (H460 and A549) cells & $\mathrm{G}_{2}-\mathrm{M}$ phase cell cycle arrest & {$[71]$} \\
\hline$\beta$-elemene & Melanoma (B16F10) cells & $\begin{array}{l}\text { Inhibition of angiogenesis via VEGF factor, } \\
\text { antiproliferative and antimetastatic activity }\end{array}$ & {$[73]$} \\
\hline$\beta$-elemene & $\begin{array}{l}\text { Human breast cancer (MCF-7/ADM) } \\
\text { cell line }\end{array}$ & $\begin{array}{l}\text { Enhancement of adriamycin effect at its nontoxic } \\
\text { concentration }\end{array}$ & {$[202]$} \\
\hline$\beta$-elemene & G-422 tumour cells in mice & Cross blood brain barrier and inhibit brain carcinomas & {$[203]$} \\
\hline$\beta$-elemene & Lung cancer (A549) cells & $\begin{array}{l}\mathrm{PI} 3 \mathrm{~K} / \mathrm{Akt} / \mathrm{mTOR} / \mathrm{p} 70 \mathrm{~S} 6 \mathrm{~K} 1 \text { signaling pathway } \\
\text { inhibition and induces autophagy }\end{array}$ & {$[204]$} \\
\hline$\beta$-elemene & $\begin{array}{l}\text { Human ovarian cancer (A2780 and } \\
\text { A2780/CP) cell lines }\end{array}$ & $\begin{array}{l}\mathrm{G}_{2}-\mathrm{M} \text { cell cycle arrests, cyclin } \mathrm{B} 1 \text { and } \mathrm{Cdc} 2 \\
\text { downregulation and elevation of p53, p21waf1/cip1, } \\
\text { p27kip1 and Gadd45 levels }\end{array}$ & [205] \\
\hline$\beta$-elemene & Liver cancer (HepG2) cells & $\mathrm{G}_{2} / \mathrm{M}$ phase cell cycle arrest and apoptosis & [206] \\
\hline$\gamma$-humulene & Colorectal cancer (HT29) cells & $\begin{array}{l}\text { Apoptosis via upregulation of the CD95 receptor and } \\
\text { CD95L on cell surface }\end{array}$ & [207] \\
\hline
\end{tabular}

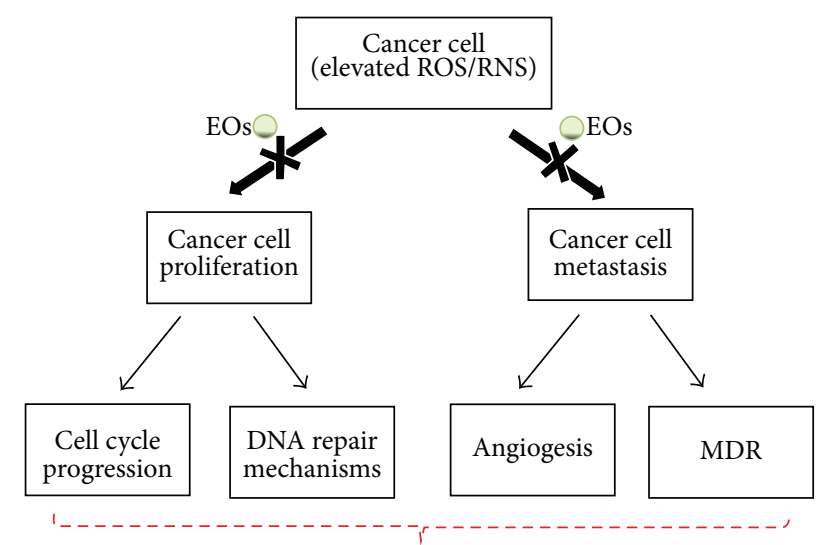

Possible route for EOs-mediated cancer cell death

FIGURE 1: Multitargeted role of Essential oils (EOs) towards cancer prevention. The EOs-mediated anticancer strategies identified so far include cell cycle arrest, apoptosis, and DNA repair mechanisms. EO reduces cancer cell proliferation, metastasis, and MDR which make them potential candidates toward adjuvant anticancer therapeutic agents.

Major compounds of Salvia libanotica EO like linalyl acetate, terpineol, and camphor have been reported to be very effective against cancer. Synergistic activity of these compounds resulted in the antiproliferative effect on the isogenic colon cancer cell lines HCT-116 (p53+/+ and p53-/-) while no such effect was observed on normal intestinal cell line under similar conditions [48]. Further, Itani et al. also concluded that, in p53+/+ cells, cancer cell death occurs via mitochondrialmediated caspase dependent pathway while in the other cells, it occurs via caspase-independent way [48]. PARP-1 protein has been shown to be modulated by the EOs and their constituents [23]. Inactivation of PARP results due to the activity of caspases leading to cancer cell death in response to treatment with EOs and their constituents. In a study, Artemisia lavandulaefolia EO and its major compound 1,8 -cineole have been shown to adopt the above route for mitochondrial and MAPKs pathways resulting in apoptosis in the mouth cancer, KB cells [23]. EO of Boswellia sacra has also been reported to induce PARP cleavage in MDA-MB-231 cells [50]. Some of the mechanisms leading to apoptosis are summarised below.

4.1.1. Increase in the ROS Levels. ROS are generated inside the cells in response to external stimuli or stress under normal conditions. Enhanced ROS levels in the abnormal cells instigate the cells to undergo apoptosis. Such response in the cancer cell on treatment with EO has been observed as an effective treatment method. EOs from Aniba rosaeodora (rosewood) were reported to induce apoptosis by increasing ROS production [51]. Similar effect has been observed by the EO of Zanthoxylum schinifolium in liver (HepG2) cancer cells which leads to apoptosis [52]. Decreased levels of cellular antioxidants like glutathione [53] and increased ROS production 
are the most commonly encountered phenomenon in cancer cells in response to the treatment with EOs that lead to cell death.

4.1.2. Effect on Akt. Akt is an important protein which also regulates p53, a tumour suppressor protein. Boswellia sacra oil influences the Akt protein expression [50]. Vapor of Litsea cubeba seed oil suppressed mTOR and pPDK1 leading to dephosphorylation of Akt protein at serine $\left(\operatorname{Ser}^{473}\right)$ and threonine $\left(\mathrm{Thr}^{308}\right.$ ), respectively, activating various caspases (caspase 3 and caspase 9) which caused programmed cell death in lung cancer cells [54]. They also reported that the cell cycle gets arrested in the lung cancer cells due to overexpression of p21 resulting from the deactivation of mdm2 due to dephosphorylated Akt protein. Further increased binding of the p21 to cyclins inhibited $\mathrm{G}_{1}-\mathrm{S}$ phase transition [54].

4.1.3. Effect on $N F-\kappa B$. Nuclear factor, NF- $\kappa \mathrm{B}$, is a transcription factor (TF) that gets activated in the tumour cells [55]. Thus, it serves as a potential target for developing anticancer drugs and blocking of this TF advocates towards anticancer activity of the natural compounds. $\alpha$-terpineol have been reported to target NF- $\kappa \mathrm{B}$ and downregulates its related genes such as $I L-1 \beta, I L 1 R 1, I F N G, I T K$, and EGFR [56]. Linalyl acetate and $\alpha$-terpineol monoterpenes act synergistically and inhibit the expression of NF- $\kappa$ B leading to cell death of colon cancer cells [57]. Human leukaemia cell line (HL-60) treated with EO of Cymbopogon flexuosus and its major constituent isointermedeol has been reported to lower NF- $\kappa \mathrm{B}$ which is one of the contributing multiple pathways resulting in apoptosis [58]. EO of Artemisia capillaries leads to NF- $\kappa \mathrm{B}-\mathrm{DNA}$ binding activation at the concentration above $0.5 \mu \mathrm{L} / \mathrm{mL}$, leading to apoptosis in the mouth cancer KB cells [47].

4.1.4. Effect on AP-1. Activator protein-1 (AP-1) is another TF which plays vital role in different processes like differentiation, proliferation, transformation, and apoptosis of the cells. Its activity is regulated by MAPK proteins which are also affected by EO treatment in cancer cells [47]. Dietary intake of $\mathrm{POH}$ results in decreasing the tumours induced by Azoxymethane- (AOM-) induced colon cancer [59]. It prevents the skin cancer induced by UV-B radiations [60] by activation of AP-1. DNA binding activity of AP-1 increases up on effective treatment of Artemisia capillaries EO resulting in apoptosis in mouth cancer cells [47]. AP-1 thus is affected by the EO treat ment and its activation mediate apoptosis in the cancer cells.

4.1.5. MAPK-Pathway. MAP kinases get activated in response to oxidative stress in the cells $[61,62]$. Various MAPKs like JNK, ERK, and p38 kinase are the signaling molecules of MAPK pathway involved in the apoptosis in cancer cell. EOs mediated apoptosis involves phosphorylated MAPK forms in the cells [62]. These forms increase with time of exposure to the EO of Artemisia capillaris in mouth cancer cells [47].

4.2. Cell Cycle Arrest. Mammalian cells have different cell cycle phases $\left(G_{1}, S, G_{2}\right.$, and metaphase) to complete their life cycle. Fidelity of the cell cycle is lost due to the lack of response to the negative regulators of cell cycle progression in the cancer cells leading to uncontrolled cell division [63]. Regulation of the genes involved in this process is also hampered. Thus, halting any cell cycle event in the cancer cell leads to prevention of their growth and division, a widely employed therapeutic strategy [64]. Various cell cycle checkpoints act as potential targets for cancer treatment [64]. Patchouli alcohol which is an important component of Pogostemon cablin EO has been reported to upregulate p21 expression and suppress cyclin D1 and cyclin-dependent kinase 4 (CDK4) expression in colorectal cancer cells with increase in dose [65]. As p21 is negative regulator of $G_{1}$ phase transition, increased expression of this protein by the action of patchouli alcohol is indicative of cell cycle inhibition [65]. Similar arresting of the $\mathrm{G}_{1}$ transition has also been reported in different types of cancer in response to various other EOs [66, 67]. EOs of Curcuma wenyujin inhibit $S / G_{2}$ phase transition leading to cancer cell death $[68] . \mathrm{G}_{2} / \mathrm{M}$ phase transition has been reported on the treatment of liver tumour (J-5) cells with diallyl trisulfide, garlic EO constituents [69]. Various constituents like geraniol, thymol, and carvacrol of EOs inhibit different phases of cell cycle [39, 70-72]. Monoterpenes act by altering the expression of cell cycle. Genes like DDIT3, IL8, and CDKNIA causing cell cycle arrest have been reported to be upregulated by frankincense oil [46]. Therefore, EOs and their constituents serve as effective anticancer substances by targeting cell cycle progression in cancer cells.

4.3. Antimetastatic and Antiangiogenic. Angiogenesis is a process that occurs in the tumours, which helps them to survive and proliferate. Inhibition of this process stops the supply of required nutrients to the cancer cell and is an efficient way to control cancer. Certain anticancer drugs target cancer cell by this way. EO of Curcuma zedoaria has been tested in vitro and in vivo for antiangiogenic effect and it was reported to exhibit antiproliferative activity against various cancer cell lines and also suppressed melanoma growth and lung metastasis in mice [73]. This action was reported to be attributed towards downregulation of matrix metalloproteinases (MMP) [73]. POH which is one of the components of many EOs has been reported as the angiogenesis inhibitor molecule [74]. EO from Citrus sinensis has been reported to inhibit angiogenesis and metastasis in colon cancer cells [75]. Inhibition of vascular endothelial growth factor (VEGF) which plays an important role in angiogenesis is the key indicator of antiangiogenic behaviour displayed by the EOs [75]. In addition, downregulation of matrix metalloproteases (MMP6) by the Citrus sinensis EO in a dose dependent manner and blockage of vascular endothelial growth factor receptor 1 (VEGFR1) also confirmed the role of EO in inhibition of metastasis in colon cancer [75]. Limonene and perillic acid are the antimetastatic molecules which are well studied in mice [76]. $\alpha$-Pinene isolated from the EO of Schinus terebinthifolius also had antimetastatic activity in the $\mathrm{C} 57 \mathrm{Bl} / 6$ mice with melanomas [77]. As both these processes are the most harmful and unique properties of the cancer cells, targeting these can prevent spreading of cancer to the other parts and inhibit proliferation of the localised tumours. Efficacy of 
the EOs in inhibiting these processes will enable potential treatment strategies for cancer therapy.

4.4. Effect on Detoxification Enzymes. Genotoxins lead to alteration of the internal antioxidants and antioxidant enzymes like superoxide dismutase (SOD), catalase (CAT), glutathione peroxidase $(\mathrm{GPx})$, and glutathione reductase (GR) along with alteration of various important body functions resulting in damage to tissues and membranes. Phase I and phase II detoxification enzymes are responsible for the degradation of the harmful compounds. Certain compounds of the EOs act as inducer of these detoxification enzymes and thus prevent the induced-toxicity and even cancer in the cell line models. Citral is the example of one such compound which increases the activity of a key phase II detoxification enzyme-glutathione-S-transferase [78]. Dietary intake of $(\mathrm{POH})$ also plays a role in the prevention of carcinogenesis induced by 4-(methylnitrosamino)-1-(3-pyridyl)-1-butanone [79].

EOs have been reported to have preventive effect on cancer treatment [80]. Varying concentrations of Allium sativum (garlic) EO were administered to mouse having diethylnitrosamine induced gastric cancer with basic diet and this EO affected phase I enzymes, SOD, CAT, and GPx activities. EO of Allium sativum has also been reported to be efficient in gastric cancer in mouse model [81]. EOs induce phase I and phase II enzymes which prevent the interaction of carcinogens with DNA. This results in chemopreventive effect of the EOs $[15,81]$.

EO of holy basil prevents fibrosarcoma tumours induced by 20 -methylcholanthrene in Swiss albino mice thighs by increasing the level of endogenous antioxidants [82]. Ocimum sanctum EO affects enzymes, namely SOD, CAT, and GST, and increases the levels of reduced glutathione, a nonenzymatic antioxidant which is responsible for decrease in the size of tumour and its incidence in the mice with the induced toxicity [82]. Salvia libanotica EO has potential to prevent the proliferation of skin papillomas induced by 7,12 dimethylbenz[a] anthracene (DMBA)- and 12-0-tetradecanoylphorbol-13-acetate (TPA) in mice [83]. Pomegranate seed oil has ability to inhibit TPA induced skin cancer in the mice [84].

Antioxidant activity of EOs has been reported to be helpful in the scavenging of free radicals generated in the diseased state, leading to the cancer prevention. Wedelia chinensis EO has high antioxidant potential which was evaluated in lung cancer cell line implanted in C57BL/6 mice [85]. Increase in the activity of antioxidant enzymes like CAT, SOD, and GPx along with increased level of glutathione was observed in the mice model, showing the preventive effect of these EOs even in the in vivo models [85]. A proposed overall mechanism by which EOs display anticancer activity is presented in Figure 2.

4.5. Modulation of DNA Damage and Repair Signaling by EOs. Increased ROS production (as discussed above) results in DNA damage and can lead to the cell death. EOs have potential to induce damages at the DNA level that drives the cancer cells towards cell death. This activity is especially harmful in cancer cells, while no such damage is encountered in the normal cells; this provides added advantage of using these EOs. Targeting DNA repair pathways is an effective treatment method currently in use in the cancer to encounter the high proliferation rate in the cancer cells $[86,87]$.

One of the peculiar properties of the EOs is that though being cytotoxic to cancer cells, these induce proliferation of the normal cells [88]. DNA repair potential is present in various EOs and their constituents. Cells pretreated with the compounds like linalool, myrcene, and eucalyptol were studied for repair activity by their recovery on the normal media and it was found that these can reduce the damage caused by hydrogen peroxide $\left(\mathrm{H}_{2} \mathrm{O}_{2}\right)$, a potential genotoxin, but their coadministration is not that beneficial [34]. Effect of the monoterpenes was dependent on the concentrations used and these had themselves induced breaks in DNA at higher concentrations [34]. Therefore, their dose response studies are important from therapeutic point of view. Camphor and thujone [89] are other monoterpenes reported to mediate via DNA repair process in the cells with induced toxicity and also known as antimutagenic in mammalian cells [89]. Thymus species EO was comparatively nontoxic to the normal fibroblast cells than MCF-7 and LNCaP human cancer cell lines [90]. $\mathrm{IC}_{50}$ values of Tetraclinis articulate $\mathrm{EO}$ on blood lymphocytes were reported almost double than for different cancer cells [91].

On the other hand, targeting the DNA repair pathways is helpful in cancer therapy as cells become reluctant to chemotherapy. Downregulation of the repair genes by the EOs can prove to be effective treatment strategy towards targeting DNA repair processes. Genes like H2AFX and HDAC4 are responsible for DNA repair and cell cycle progression and were found to be suppressed by frankincense oil in human bladder cancer (J82) cells using microarray analysis [46]. Therefore, EOs inhibit the cancer cell progression and thereby showing anticancer properties.

More specifically, the DNA polymerases are the enzymes involved in DNA repair and replication (DNA polymerases $\alpha, \delta$, and $\varepsilon$ ). These have been reported to be very effective targets in the development of drugs for cancer treatment. EOs inhibit the activity of the DNA polymerases [11] and therefore can be used as chemotherapeutic agents in cancer treatment. Chamomile EO was found to be very strong mammalian polymerase $(\lambda$ and $\alpha)$ inhibitor among many other EOs tested which account for their increased therapeutic potential against cancer [11]. As polymerase $\alpha$ is a DNA replicative polymerase and polymerase $\lambda$ is a DNA repair/recombination polymerase, hence inhibition of both these polymerases will be helpful in cancer therapeutics [11].

The important DNA damage signaling protein, namely, PARP-1, is most abundantly found nuclear protein almost in all eukaryotes other than yeast. It is the first protein to act on the damaged DNA (single strand DNA and double strand DNA breaks) and initiates the DNA repair by the process of PARsylation and recruiting other DNA repair proteins associated with Base Excision Repair (BER) [86, 92] and nonhomologous end joining (NHEJ) [93]. Many EOs and their constituents lead to PARP cleavage [68]. Proteolytic cleavage of PARP-1 by the action of EOs might be indicative of modification of the DNA repair process in the cancer cells. 


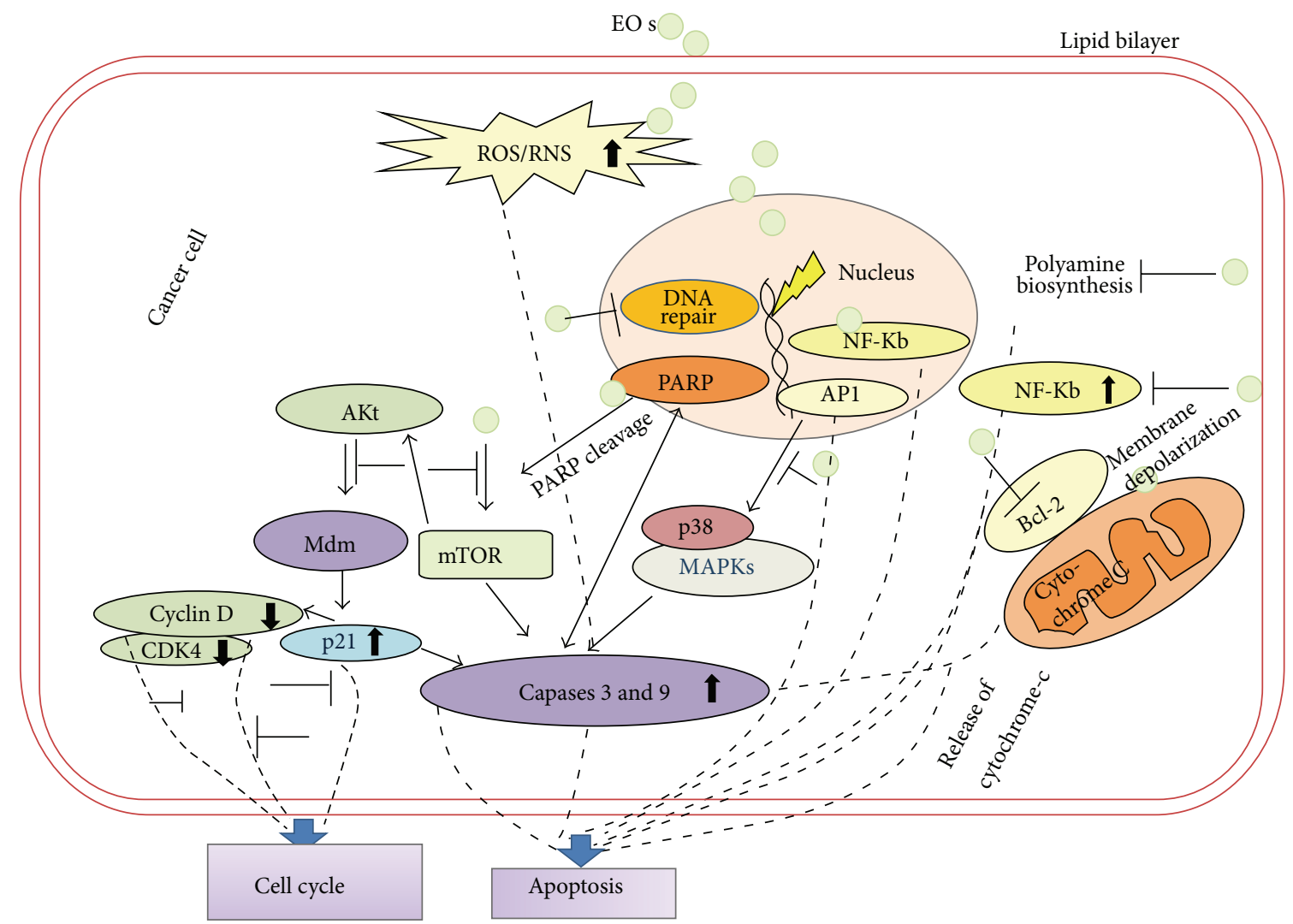

FIGURE 2: EOs and their constituents target multiple pathways in cancer cells. EOs by virtue have cell membrane permeability and act on different cellular targets involved in various pathways. EOs increase intracellular ROS/RNS levels which results in apoptosis in cancer cells. Inhibition of Akt, mTOR, and MAPK pathways at different steps by EOs leads to corresponding up-/downregulation of various key biomolecules (and corresponding genes which are not shown in the figure). Alteration in expression of NF- $\kappa \mathrm{B}$ by EOs and further binding of NF- $\kappa \mathrm{B}$ to DNA result in apoptosis in cancer cells. Dephosphorylation of Akt by the action of EOs results in overexpression of p21, which either induces apoptosis by increasing caspases level or results in cell cycle arrest by binding to cyclins. In addition, EOs-induced mitochondrial stress leads to activation of Bcl-2 and membrane depolarisation resulting in enhanced release of cytochrome-C to the cytoplasm which induces apoptotic cell death in cancer cells. EOs also modulate DNA repair mechanisms by acting as DNA polymerase inhibitors and lead to PARP cleavage which also results in apoptosis in cancer cells.

More elaborative studies are still required in the determination of the role of EOs in modulation of different repair pathways like BER and NHEJ in cancer prevention.

\section{Multidrug Resistance (MDR) in Cancer: A Potential Set Back}

Multidrug resistance (MDR) is the most frequently encountered problem in the cancer patients, which makes most of the routinely used anticancer drugs ineffective [7, 94]. Lots of research are oriented on circumventing this problem. This arises due to different mechanisms like induction of repair of the damaged DNA in response to drug, change in drug uptake capability, and change in the level and response of the targeted enzymes. Adenosine triphosphate cassette (ABC)-transporter family proteins confer MDR due to their increased activity [95]. EOs can circumvent the reluctance of tumours to respond to the cytotoxic drugs [96]. EOs of thyme are effective against widely used drugs like Adriamycin, Vincristine, and Cisplatin resistant ovarian cancer cell lines and, in addition, tumour size reduction was also observed in vivo which indicates the efficacy of the $\mathrm{EO}$ in mammalian system [96, 97]. Juniperus excels EO was effective against MDR P-glycoprotein-expressing CEM/ADR5000 leukemia cells and reversed their resistance indicating the use of EO in MDR treatment in cancer [98]. Melaleuca alternifolia, 
tea tree oil, can ameliorate Adriamycin resistance in human melanoma cells and terpinen-1-ol is responsible for this activity [99]. Various EO constituents are reported as the antiMDR molecules and are summarized below.

Linalool, monoterpene alcohol, is a constituent of many EOs and is reported to increase the therapeutic potential of Doxorubicin in breast cancer cells MCF-7 (adriamycin resistant) by increasing its accumulation in these cells for effective response [100]. It has also been reported to cause membrane damage in the Epirubicin-resistant lung cancer, H1299 cells [101]. Emergence of Dox resistance is the other most widely encountered chemotherapeutic hurdle [102] in the treatment of cancer patients. Thymoquinone (TQ) is the constituent of Nigella sativa and various other EOs have been found to prevent Dox induced resistance in breast cancer (MCF-7/ Dox) cells. It inhibits their growth, induces apoptosis by upregulation of phosphatase and tensin homolog (PTEN), leading to downregulation of Akt cell survival protein, and causes cell cycle arrest at $\mathrm{G}_{2} / \mathrm{M}$ phase [103]. Use of the EOs as dietary supplements and coadministration with drugs can enhance the response to the treatment. However, limited studies are available in this aspect but EOs and their active constituents are the promising avenues for combating MDR in cancer patients. Hence, some EOs can be used as combinational therapy in cancer patients due to their beneficial effects after indepth research on the capability to overcome MDR.

\section{Prevention of Side Effects of Cancer Treatment}

Cancer patients suffer from different side effects which can be preferentially reduced by alternative methods. EOs are used in the aromatherapy for reducing the agony of brain cancer patients [104]. EO is efficient in depression and reduction of anxiety in cancer patients [105]. Cancer patients undergoing chemotherapy, one of the most frequently used treatment method in cancer, are prone to various side effects [106]. These are nausea and vomiting. Mentha spicata and $M$. piperita have been found to be effective in overcoming these emetic conditions (chemotherapy-induced nausea and vomiting, CINV) along with the reduction of expenditure on treatment in the cancer patients undergoing chemotherapy [107]. EOs of Leptospermum scoparium and Kunzea ericoides were reported to prevent mucositis in the head and neck cancer patients undergoing radiotherapy when used in the preparation of mouthwash [108]. Some cancer patients having metastatic tumorigenic ulcers of skin develop necrosis and malodour [109]. Patients suffering from such malodour were reported to have improvement in their state on treatment of these ulcers with the mixture of EOs having eucalyptus, melaleuca, lemongrass, lemon, clove leaf, and thyme on a $40 \%$ ethanol base [110]. Lavender EO is widely used in aromatherapy and is found to be beneficial in reducing the distress in cancer patients [111]. Hence, EOs serve as the valuable preparations in amelioration of the side effects and sufferings of the cancer patients.

\section{Conclusions and Future Perspectives}

EOs have been used in medicine from the ancient times and the present review is an attempt to highlight their therapeutic and chemopreventive value with major emphasis on the mechanistic approaches. Main aim of summarizing the research in this area is to provide better understanding of various pathways and mode of action of different EOs. EO constituents are potent in cancer prevention and treatment. Novel potent anticancer molecules can be found in EOs which can further be exploited in therapeutics. EOs can efficiently be exploited in pharmaceutical preparations with more research and some of them are already in the different phases of clinical trials. EOs are more effective in the preliminary studies than the individual constituents. Further, EOs and their constituents can be evaluated as therapeutic agents and can be used in complementation to standard therapies. Research on EOs as anticancer therapeutic agents is still in growing stage and immense potential of the EOs needs to be explored due to the lack of target specific release. Further, studies including clinical trials are required along with the use of advanced techniques for the targeted organ-specific release of the EOs for making the treatment more effective.
Abbreviations
NCBI: National Center for Biotechnology Information
IARC: International Agency for Research on Cancer
WHO: World Health Organisation
EOs: $\quad$ Essential oils
DNA: Deoxyribonucleic acid
PubMed: Publisher Medline
POH: Perillyl alcohol
ERK: Extracellular signal-regulated kinase
NF- $\kappa$ B: Nuclear factor
kappa-light-chain-enhancer of activated
B cells
AP-1: Activator protein-1
CDK4: Cyclin-dependent kinase 4
VEGFR: Vascular endothelial growth factor receptor
VEGF: Vascular endothelial growth factor
MMP: Matrix Metalloproteases
MAPK: Mitogen-activated protein kinases
PARP: Poly(ADP-Ribose) polymerase
ROS: Reactive oxygen species
SOD: Superoxide dismutase
CAT: Catalase
GPx: Glutathione peroxidase
GR: Glutathione reductase
GST: Glutathione-S-transferase
DMBA: Dimethylbenz[A] anthracene
mTOR: Mammalian target of rapamycin
Mdm: Mouse double minute 2 homolog
p21: $\quad$ CDK-interacting protein 1
TPA: 12-0-Tetradecanoylphorbol-13-acetate 


$\begin{array}{ll}\mathrm{H}_{2} \mathrm{O}_{2}: & \text { Hydrogen peroxide } \\ \text { BER: } & \text { Base excision repair } \\ \text { NHEJ: } & \text { Nonhomologous end joining } \\ \text { MDR: } & \text { Multidrug resistance } \\ \text { ABC-Transporter: } & \text { Adenosine Triphosphate Cassette } \\ & \text { (ABC)-Transporter } \\ \text { PTEN: } & \text { Phosphatase and tensin homolog } \\ \text { TQ: } & \text { Thymoquinone. }\end{array}$

Conflict of Interests

The authors have declared that no conflict of interests exists.

\section{Acknowledgments}

This research was supported by the Science and Engineering Research Board, New Delhi, India (SR/FT/LS-66/2011), Grant awarded to Sunil Mittal, and UGC-BSR start-up Grant no. 20-39(12)/2013(BSR) awarded to Anil K. Mantha In addition, Nandini Gautam acknowledges institutional financial support from CUPB. The authors thank Dr. Raj Kumar, Assistant Professor, Centre for Chemical and Pharmaceutical Sciences, for critical comments; J. Nagendra Babu, Assistant Professor, Centre for Environmental Science and Technology, for providing technical assistance; and Neetu Purohit, Centre for Comparative Literature, Central University of Punjab, Bathinda, Punjab (India), for proof reading the paper for typographic and linguistic errors. Because of the limited focus of the paper, many appropriate references could not be included, for which the authors apologize. The CUPB publication number provided for this review is $\mathrm{P}-010 / 14$.

\section{References}

[1] National Cancer Institute, "Cancer Topics : Environment," 2013, http://www.cancer.gov/cancertopics/understandingcancer/environment/AllPages.

[2] J. Ferlay, I. Soerjomataram, M. Ervik et al., GLOBOCAN, 2012 v1. 0, Cancer Incidence and Mortality Worldwide: IARC CancerBase, no. 11 Lyon, France: International Agency for Research on Cancer, 2013 http://www.iarc.fr/en/media-centre/pr/2013/ pdfs/pr223_E.pdf.

[3] J. Ferlay, H. R. Shin, F. Bray, D. Forman, C. Mathers, and D. M. Parkin, "Estimates of worldwide burden of cancer in 2008: GLOBOCAN 2008," International Journal of Cancer, vol. 127, no. 12, pp. 2893-2917, 2010.

[4] R. Takiar, D. Nadayil, and A. Nandakumar, "Projections of number of cancer cases in India (2010-2020) by cancer groups," Asian Pacific Journal of Cancer Prevention, vol. 11, no. 4, pp. 1045-1049, 2010.

[5] A. Jemal, F. Bray, M. M. Center, J. Ferlay, E. Ward, and D. Forman, "Global cancer statistics," CA Cancer Journal for Clinicians, vol. 61, no. 2, pp. 69-90, 2011.

[6] L. Naumovski, J. P. Quinn, D. Miyashiro et al., "Outbreak of ceftazidime resistance due to a novel extended-spectrum $\beta$ lactamase in isolates from cancer patients," Antimicrobial Agents and Chemotherapy, vol. 36, no. 9, pp. 1991-1996, 1992.

[7] K. Nooter and H. Herweijer, "Multidrug resistance (mdr) genes in human cancer," British Journal of Cancer, vol. 63, no. 5, pp. 663-669, 1991.
[8] P. K. Mukherjee, "Exploring botanicals in Indian system of medicine-regulatory perspectives," Clinical Research and Regulatory Affairs, vol. 20, no. 3, pp. 249-264, 2003.

[9] G. M. Cragg and D. J. Newman, "Plants as a source of anticancer agents," Journal of Ethnopharmacology, vol. 100, no. 1-2, pp. 72-79, 2005.

[10] J. Q. Yu, J. C. Lei, X. Q. Zhang et al., "Anticancer, antioxidant and antimicrobial activities of the essential oil of Lycopus lucidus Turcz. var. hirtus Regel," Food Chemistry, vol. 126, no. 4, pp. 1593-1598, 2011.

[11] M. Mitoshi, I. Kuriyama, H. Nakayama et al., "Effects of essential oils from herbal plants and citrus fruits on DNA polymerase inhibitory, cancer cell growth inhibitory, antiallergic, and antioxidant activities," Journal of Agricultural and Food Chemistry, vol. 60, no. 45, pp. 11343-11350, 2012.

[12] National Cancer Institute, "Aromatherapy and Essential Oils (PD Q)," http://www.cancer.gov/cancertopics/pdq/cam/aromatherapy/healthprofessional.

[13] Y. Bhalla, V. K. Gupta, and V. Jaitak, "Anticancer activity of essential oils: a review," Journal of the Science of Food and Agriculture, vol. 93, no. 15, pp. 3643-3653, 2013.

[14] O. Y. Celiktas, E. Kocabas, E. Bedir, F. V. Sukan, T. Ozek, and K. H. C. Baser, "Antimicrobial activities of methanol extracts and essential oils of Rosmarinus officinalis, depending on location and seasonal variations," Food Chemistry, vol. 100, no. 2, pp. 553-559, 2007.

[15] A. Özkan and A. Erdoǧan, "A comparative evaluation of antioxidant and anticancer activity of essential oil from origanum onites (lamiaceae) and its two major phenolic components," Turkish Journal of Biology, vol. 35, no. 6, pp. 735-742, 2011.

[16] H. G. Lancelle, O. S. Giordano, M. E. Sosa, and C. E. Tonn, "Chemical composition of four essential oils from Eupatorium spp. biological activities toward Tribolium castaneum (Coleoptera: Tenebrionidae)," Revista de la Sociedad Entomológica Argentina, vol. 68, no. 3-4, pp. 329-338, 2009.

[17] B. Tepe, E. Donmez, M. Unlu et al., "Antimicrobial and antioxidative activities of the essential oils and methanol extracts of Salvia cryptantha (Montbret et Aucher ex Benth.) and Salvia multicaulis (Vahl)," Food Chemistry, vol. 84, no. 4, pp. 519-525, 2004.

[18] M. Lu, Z. Han, and L. Yao, "In vitro and in vivo antimicrobial efficacy of essential oils and individual compounds against Phytophthora parasitica var. nicotianae," Journal of Applied Microbiology, vol. 115, no. 1, pp. 187-198, 2013.

[19] F. Bakkali, S. Averbeck, D. Averbeck, and M. Idaomar, "Biological effects of essential oils-a review," Food and Chemical Toxicology, vol. 46, no. 2, pp. 446-475, 2008.

[20] M. Boukhris, M. Bouaziz, I. Feki, H. Jemai, A. El Feki, and S. Sayadi, "Hypoglycemic and antioxidant effects of leaf essential oil of Pelargonium graveolens L'Hér. in alloxan induced diabetic rats," Lipids in Health and Disease, vol. 11, article 81, 2012.

[21] N. S. L. Perry, P. J. Houghton, J. Sampson et al., "In-vitro activity of In-vitro (Spanish sage) relevant to treatment of Alzheimer's disease," Journal of Pharmacy and Pharmacology, vol. 53, no. 10, pp. 1347-1356, 2001.

[22] R. P. C. Ferraz, D. S. Bomfim, N. C. Carvalho et al., "Cytotoxic effect of leaf essential oil of Lippia gracilis Schauer (Verbenaceae)," Phytomedicine, vol. 20, no. 7, pp. 615-621, 2013.

[23] J. D. Cha, Y. H. Kim, and J. Y. Kim, "Essential oil and 1,8-cineole from Artemisia lavandulaefolia induces apoptosis in KB Cells via mitochondrial stress and caspase activation," Food Science and Biotechnology, vol. 19, no. 1, pp. 185-191, 2010. 
[24] G. K. Jayaprakasha, K. N. C. Murthy, R. M. Uckoo, and B. S. Patil, "Chemical composition of volatile oil from Citrus limettioides and their inhibition of colon cancer cell proliferation," Industrial Crops and Products, vol. 45, pp. 200-207, 2013.

[25] M. R. F. Gomes, R. S. Schuh, A. L. B. Jacques et al., "Citotoxic activity evaluation of essential oils and nanoemulsions of Drimys angustifolia and D. brasiliensis on human glioblastoma (U$138 \mathrm{MG}$ ) and human bladder carcinoma (T24) cell lines in vitro," Brazilian Journal of Pharmacognosy, vol. 23, no. 2, pp. 259-267, 2013.

[26] S. K. Nanyonga, A. Opoku, F. B. Lewu, A. O. Oyedeji, and M. Singh, "Chemical composition, antioxidant activity and cytotoxicity of the essential oils of the leaves and stem of Tarchonanthus camphoratus," African Journal of Pharmacy and Pharmacology, vol. 7, no. 7, pp. 360-367, 2013.

[27] A. Akrout, L. A. Gonzalez, H. El Jani, and P. C. Madrid, "Antioxidant and antitumor activities of Artemisia campestris and Thymelaea hirsuta from southern Tunisia," Food and Chemical Toxicology, vol. 49, no. 2, pp. 342-347, 2011.

[28] Y. $\mathrm{Zu}, \mathrm{H}$. Yu, L. Liang et al., "Activities of ten essential oils towards Propionibacterium acnes and PC-3, A-549 and MCF-7 cancer cells," Molecules, vol. 15, no. 5, pp. 3200-3210, 2010.

[29] S. Jayakumar, A. Madankumar, S. Asokkumar et al., "Potential preventive effect of carvacrol against diethylnitrosamineinduced hepatocellular carcinoma in rats," Molecular and Cellular Biochemistry, vol. 360, no. 1-2, pp. 51-60, 2012.

[30] J. A. Elegbede, C. E. Elson, A. Qureshi, M. A. Tanner, and M. N. Gould, "Inhibition of DMBA-induced mammary cancer by the monoterpene d-limonene," Carcinogenesis, vol. 5, no. 5, pp. 661-664, 1984.

[31] S. Carnesecchi, Y. Schneider, J. Ceraline et al., "Geraniol, a component of plant essential oils, inhibits growth and polyamine biosynthesis in human colon cancer cells," Journal of Pharmacology and Experimental Therapeutics, vol. 298, no. 1, pp. 197-200, 2001.

[32] S. Carnesecchi, K. Langley, F. Exinger, F. Gosse, and F. Raul, "Geraniol, a component of plant essential oils, sensitizes human colonic cancer cells to 5-fluorouracil treatment," Journal of Pharmacology and Experimental Therapeutics, vol.301, no. 2, pp. 625-630, 2002.

[33] S. Carnesecchi, R. Bras-Gonçalves, A. Bradaia et al., "Geraniol, a component of plant essential oils, modulates DNA synthesis and potentiates 5-fluorouracil efficacy on human colon tumor xenografts," Cancer Letters, vol. 215, no. 1, pp. 53-59, 2004.

[34] D. Mitić-Ćulafić, B. Žegura, B. Nikolić, B. Vuković-Gačić, J. Knežević-Vukčević, and M. Filipič, "Protective effect of linalool, myrcene and eucalyptol against t-butyl hydroperoxide induced genotoxicity in bacteria and cultured human cells," Food and Chemical Toxicology, vol. 47, no. 1, pp. 260-266, 2009.

[35] T. G. do Vale, E. C. Furtado, J. G. Santos Jr., and G. S. B. Viana, "Central effects of citral, myrcene and limonene, constituents of essential oil chemotypes from Lippia alba (mill.) N.E. Brown," Phytomedicine, vol. 9, no. 8, pp. 709-714, 2002.

[36] M. Koyama, Y. Sowa, T. Hitomi et al., "Perillyl alcohol causes $\mathrm{G}_{1}$ arrest through p15INK4b and p21 WAF1/Cipl induction," Oncology Reports, vol. 29, no. 2, pp. 779-784, 2013.

[37] S. L. da Silva, J. D. S. Chaar, P. D. M. S. Figueiredo, and T. Yano, "Cytotoxic evaluation of essential oil from Casearia sylvestris Sw on human cancer cells and erythrocytes," Acta Amazonica, vol. 38, no. 1, pp. 107-112, 2008.
[38] J. Legault and A. Pichette, "Potentiating effect of $\beta$-caryophyllene on anticancer activity of $\alpha$-humulene, isocaryophyllene and paclitaxel," Journal of Pharmacy and Pharmacology, vol. 59, no. 12, pp. 1643-1647, 2007.

[39] A. Jaafari, M. Tilaoui, H. A. Mouse et al., "Comparative study of the antitumor effect of natural monoterpenes: relationship to cell cycle analysis," Brazilian Journal of Pharmacognosy, vol. 22, no. 3, pp. 534-540, 2012.

[40] D. D. Deb, G. Parimala, S. Saravana Devi, and T. Chakraborty, "Effect of thymol on peripheral blood mononuclear cell PBMC and acute promyelotic cancer cell line HL-60," ChemicoBiological Interactions, vol. 193, no. 1, pp. 97-106, 2011.

[41] W. Chaouki, D. Y. Leger, B. Liagre, J. L. Beneytout, and M. Hmamouchi, "Citral inhibits cell proliferation and induces apoptosis and cell cycle arrest in MCF-7 cells," Fundamental and Clinical Pharmacology, vol. 23, no. 5, pp. 549-556, 2009.

[42] G. H. Ripple, M. N. Gould, J. A. Stewart et al., "Phase I clinical trial of perillyl alcohol administered daily," Clinical Cancer Research, vol. 4, no. 5, pp. 1159-1164, 1998.

[43] H. H. Bailey, D. Levy, L. S. Harris et al., "A phase II trial of daily perillyl alcohol in patients with advanced ovarian cancer: eastern cooperative oncology group study E2E96," Gynecologic Oncology, vol. 85, no. 3, pp. 464-468, 2002.

[44] P. M. Döll-Boscardin, A. Sartoratto, B. H. L. de Noronha Sales Maia et al., "In vitro cytotoxic potential of essential oils of Eucalyptus benthamii and its related terpenes on tumor cell lines," Evidence-based Complementary and Alternative Medicine, vol. 2012, Article ID 342652, 8 pages, 2012.

[45] V. Cardile, A. Russo, C. Formisano et al., "Essential oils of Salvia bracteata and Salvia rubifolia from Lebanon: chemical composition, antimicrobial activity and inhibitory effect on human melanoma cells," Journal of Ethnopharmacology, vol. 126, no. 2, pp. 265-272, 2009.

[46] M. B. Frank, Q. Yang, J. Osban et al., "Frankincense oil derived from Boswellia carteri induces tumor cell specific cytotoxicity," BMC Complementary and Alternative Medicine, vol. 9, article 6, 2009.

[47] J. D. Cha, S. E. Moon, H. Y. Kim, I. H. Cha, and K. Y. Lee, "Essential oil of artemisia capillaris induces apoptosis in $\mathrm{KB}$ cells via mitochondrial stress and caspase activation mediated by MAPK-stimulated signaling pathway," Journal of Food Science, vol. 74, no. 9, pp. T75-T81, 2009.

[48] W. S. Itani, S. H. El-Banna, S. B. Hassan, R. L. Larsson, A. Bazarbachi, and H. U. Gali-Muhtasib, "Anti colon cancer components from lebanese sage (Salvia libanotica) essential oil: mechanistic basis," Cancer Biology and Therapy, vol. 7, no. 11, pp. 1765-1773, 2008.

[49] C. Soldani and A. I. Scovassi, "Poly(ADP-ribose) polymerase-1 cleavage during apoptosis: an update," Apoptosis, vol. 7, no. 4, pp. 321-328, 2002.

[50] M. M. Suhail, W. Wu, A. Cao et al., "Boswellia sacra essential oil induces tumor cell-specific apoptosis and suppresses tumor aggressiveness in cultured human breast cancer cells," $B M C$ Complementary and Alternative Medicine, vol. 11, article 129, 2011.

[51] J. Sœur, L. Marrot, P. Perez et al., "Selective cytotoxicity of Aniba rosaeodora essential oil towards epidermoid cancer cells through induction of apoptosis," Mutation Research-Genetic Toxicology and Environmental Mutagenesis, vol. 718, no. 1-2, pp. 24-32, 2011. 
[52] S. Y. Paik, K. H. Koh, S. M. Beak, S. H. Paek, and J. A. Kim, "The essential oils from Zanthoxylum schinifolium pericarp induce apoptosis of HepG2 human hepatoma cells through increased production of reactive oxygen species," Biological and Pharmaceutical Bulletin, vol. 28, no. 5, pp. 802-807, 2005.

[53] J. Legault, W. Dahl, E. Debiton, A. Pichette, and J.-C. Madelmont, "Antitumor activity of balsam fir oil: Production of reactive oxygen species induced by $\alpha$-humulene as possible mechanism of action," Planta Medica, vol. 69, no. 5, pp. 402-407, 2003.

[54] S. Seal, P. Chatterjee, S. Bhattacharya et al., "Vapor of volatile oils from Litsea cubeba seed induces apoptosis and causes cell cycle arrest in lung cancer cells," PLoS ONE, vol. 7, no. 10, Article ID e47014, 2012.

[55] D. W. Kim, M. A. Sovak, G. Zanieski et al., "Activation of NF- $\kappa$ B/Rel occurs early during neoplastic transformation of mammary cells," Carcinogenesis, vol. 21, no. 5, pp. 871-879, 2000.

[56] S. B. Hassan, H. Gali-Muhtasib, H. Göransson, and R. Larsson, "Alpha terpineol: a potential anticancer agent which acts through suppressing NF- $\kappa \mathrm{B}$ signalling," Anticancer Research, vol. 30, no. 6, pp. 1911-1919, 2010.

[57] S. J. Deeb, Enhancement of Cell Death by Linalyl Acetate and $\alpha$-terpineol through Targeting the Nuclear factor- $\kappa b$ Activation Pathway in Human Colon Cancer Cells, American University of Beirut, 2009.

[58] A. Kumar, F. Malik, S. Bhushan et al., "An essential oil and its major constituent isointermedeol induce apoptosis by increased expression of mitochondrial cytochrome $c$ and apical death receptors in human leukaemia HL-60 cells," Chemico-Biological Interactions, vol. 171, no. 3, pp. 332-347, 2008.

[59] B. S. Reddy, C. X. Wang, H. Samaha et al., "Chemoprevention of colon carcinogenesis by dietary perillyl alcohol," Cancer Research, vol. 57, no. 3, pp. 420-425, 1997.

[60] M. Barthelman, W. Chen, H. L. Gensler, C. Huang, Z. Dong, and G. T. Bowden, "Inhibitory effects of perillyl alcohol on UVBinduced murine skin cancer and AP-1 transactivation," Cancer Research, vol. 58, no. 4, pp. 711-716, 1998.

[61] Y. W. Ki, J. H. Park, J. E. Lee, I. C. Shin, and H. C. Koh, "JNK and p38 MAPK regulate oxidative stress and the inflammatory response in chlorpyrifos-induced apoptosis," Toxicology Letters, vol. 218, no. 3, pp. 235-245, 2013.

[62] J. L. Martindale and N. J. Holbrook, "Cellular response to oxidative stress: signaling for suicide and survival," Journal of Cellular Physiology, vol. 192, no. 1, pp. 1-15, 2002.

[63] S. Diaz-Moralli, M. Tarrado-Castellarnau, A. Miranda, and M. Cascante, "Targeting cell cycle regulation in cancer therapy," Pharmacology and Therapeutics, vol. 138, no. 2, pp. 255-271, 2013.

[64] B. Gabrielli, K. Brooks, and S. Pavey, "Defective cell cycle checkpoints as targets for anti-cancer therapies," Frontiers in Pharmacology, vol. 3, article 9, 2012.

[65] J. B. Jeong, J. Choi, Z. Lou, X. Jiang, and S.-H. Lee, "Patchouli alcohol, an essential oil of Pogostemon cablin, exhibits antitumorigenic activity in human colorectal cancer cells," International Immunopharmacology, vol. 16, no. 2, pp. 184-190, 2013.

[66] L. Cai, H. Ye, X. Li et al., "Chemical constituents of volatile oil from Pyrolae herba and antiproliferative activity against SW1353 human chondrosarcoma cells," International Journal of Oncology, vol. 42, no. 4, pp. 1452-1458, 2013.
[67] X. Ni, M. M. Suhail, Q. Yang et al., "Frankincense essential oil prepared from hydrodistillation of Boswellia sacra gum resins induces human pancreatic cancer cell death in cultures and in a xenograft murine model," BMC Complementary and Alternative Medicine, vol. 12, article 253, 2012.

[68] Y. Xiao, F. Q. Yang, S. P. Li, G. Hu, S. M. Y. Lee, and Y. T. Wang, "Essential oil of Curcuma wenyujin induces apoptosis in human hepatoma cells," World Journal of Gastroenterology, vol. 14, no. 27, pp. 4309-4318, 2008.

[69] C. C. Wu, J. G. Chung, S. J. Tsai, J. H. Yang, and L. Y. Sheen, "Differential effects of allyl sulfides from garlic essential oil on cell cycle regulation in human liver tumor cells," Food and Chemical Toxicology, vol. 42, no. 12, pp. 1937-1947, 2004.

[70] S. Bardon, V. Foussard, S. Fournel, and A. Loubat, "Monoterpenes inhibit proliferation of human colon cancer cells by modulating cell cycle-related protein expression," Cancer Letters, vol. 181, no. 2, pp. 187-194, 2002.

[71] G. Wang, X. Li, F. Huang et al., "Antitumor effect of $\beta$-elemene in non-small-cell lung cancer cells is mediated via induction of cell cycle arrest and apoptotic cell death," Cellular and Molecular Life Sciences, vol. 62, no. 7-8, pp. 881-893, 2005.

[72] H. Y. Wang, B. Cai, C. B. Cui, D. Y. Zhang, and B. F. Yang, "Vitexicarpin, a flavonoid from Vitex trifolia L., induces apoptosis in K562 cells via mitochondria-controlled apoptotic pathway," Yaoxue Xuebao, vol. 40, no. 1, pp. 27-31, 2005.

[73] W. Chen, Y. Lu, J. Wu, M. Gao, A. Wang, and B. Xu, "Betaelemene inhibits melanoma growth and metastasis via suppressing vascular endothelial growth factor-mediated angiogenesis," Cancer Chemotherapy and Pharmacology, vol. 67, no. 4, pp. 799-808, 2011.

[74] H. Loutrari, M. Hatziapostolou, V. Skouridou et al., "Perillyl alcohol is an angiogenesis inhibitor," Journal of Pharmacology and Experimental Therapeutics, vol. 311, no. 2, pp. 568-575, 2004.

[75] K. N. Chidambara Murthy, G. K. Jayaprakasha, and B. S. Patil, "D-limonene rich volatile oil from blood oranges inhibits angiogenesis, metastasis and cell death in human colon cancer cells," Life Sciences, vol. 91, no. 11-12, pp. 429-439, 2012.

[76] T. J. Raphael and G. Kuttan, "Effect of naturally occurring monoterpenes carvone, limonene and perillic acid in the inhibition of experimental lung metastasis induced by B16F-10 melanoma cells," Journal of Experimental and Clinical Cancer Research, vol. 22, no. 3, pp. 419-424, 2003.

[77] A. L. Matsuo, C. R. Figueiredo, D. C. Arruda et al., " $\alpha$-Pinene isolated from Schinus terebinthifolius Raddi (Anacardiaceae) induces apoptosis and confers antimetastatic protection in a melanoma model," Biochemical and Biophysical Research Communications, vol. 411, no. 2, pp. 449-454, 2011.

[78] Y. Nakamura, M. Miyamoto, A. Murakami, H. Ohigashi, T. Osawa, and K. Uchida, "A phase II detoxification enzyme inducer from lemongrass: Identification of citral and involvement of electrophilic reaction in the enzyme induction," Biochemical and Biophysical Research Communications, vol. 302, no. 3, pp. 593-600, 2003.

[79] L. E. Lantry, Z. Zhang, F. Gao et al., "Chemopreventive effect of perillyl alcohol on 4-(methylnitrosamino)-1-(3-pyridyl)-1butanone induced tumorigenesis in $(\mathrm{C} 3 \mathrm{H} / \mathrm{HeJ} \mathrm{X} \mathrm{A/J)F1} \mathrm{mouse}$ lung," Journal of Cellular Biochemistry, vol. 67, supplement 27, pp. 20-25, 1998. 
[80] W. Q. Li, C. H. Jiang, S. S. Chu, M. X. Zuo, and Z. L. Liu, "Chemical composition and toxicity against Sitophilus zeamais and Tribolium castaneum of the essential oil of Murraya exotica aerial parts," Molecules, vol. 15, no. 8, pp. 5831-5839, 2010.

[81] R. Li, W. C. Chen, W. P. Wang, W. Y. Tian, and X. G. Zhang, "Extraction of essential oils from garlic (Allium sativum) using ligarine as solvent and its immunity activity in gastric cancer rat," Medicinal Chemistry Research, vol. 19, no. 9, pp. 1092-1105, 2010.

[82] J. Prakash and S. K. Gupta, "Chemopreventive activity of Ocimum sanctum seed oil," Journal of Ethnopharmacology, vol. 72, no. 1-2, pp. 29-34, 2000.

[83] H. U. Gali-Muhtasib and N. I. Affara, "Chemopreventive effects of sage oil on skin papillomas in mice," Phytomedicine, vol. 7, no. 2, pp. 129-136, 2000.

[84] J. J. Hora, E. R. Maydew, E. P. Lansky, and C. Dwivedi, "Chemopreventive effects of pomegranate seed oil on skin tumor development in CD1 mice," Journal of Medicinal Food, vol. 6, no. 3, pp. 157-161, 2003.

[85] A. Manjamalai and V. M. Berlin Grace, "Antioxidant activity of essential oils from Wedelia chinensis (osbeck) in vitro and in vivo lung cancer bearing C57BL/6 mice," Asian Pacific Journal of Cancer Prevention, vol. 13, no. 7, pp. 3065-3071, 2012.

[86] A. K. Mantha, "APE1: a molecule of focus with neuroprotective and anti-cancer properties," Journal of Biotechnology \& Biomaterials, vol. 3, article e120, 2013.

[87] M. R. Kelley, L. Cheng, R. Foster et al., "Elevated and altered expression of the multifunctional DNA base excision repair and redox enzyme Ape1/ref-1 in prostate cancer," Clinical Cancer Research, vol. 7, no. 4, pp. 824-830, 2001.

[88] A. Jaafari, H. A. Mouse, E. M. Rakib et al., "Chemical composition and antitumor activity of different wild varieties of Moroccan thyme," Brazilian Journal of Pharmacognosy, vol. 17, no. 4, pp. 477-491, 2007.

[89] B. Nikolić, D. Mitić-Ćulafić, B. Vuković-Gačić, and J. KneževićVukčević, "Modulation of genotoxicity and DNA repair by plant monoterpenes camphor, eucalyptol and thujone in Escherichia coli and mammalian cells," Food and Chemical Toxicology, vol. 49, no. 9, pp. 2035-2045, 2011.

[90] A. I. Hussain, F. Anwar, S. A. S. Chatha et al., "Chemical composition and bioactivity studies of the essential oils from two Thymus species from the Pakistani flora," LWT-Food Science and Technology, vol. 50, no. 1, pp. 185-192, 2013.

[91] J. A. Buhagiar, M. T. C. Podesta, A. P. Wilson, M. J. Micallef, and S. Ali, "The induction of apoptosis in human melanoma, breast and ovarian cancer cell lines using an essential oil extract from the conifer Tetraclinis articulata," Anticancer Research, vol. 19, no. 6 B, pp. 5435-5443, 1999.

[92] M. L. Hegde, A. K. Mantha, T. K. Hazra, K. K. Bhakat, S. Mitra, and B. Szczesny, "Oxidative genome damage and its repair: Implications in aging and neurodegenerative diseases," Mechanisms of Ageing and Development, vol. 133, no. 4, pp. 157-168, 2012.

[93] M. Wang, W. Wu, W. Wu et al., "PARP-1 and Ku compete for repair of DNA double strand breaks by distinct NHEJ pathways," Nucleic Acids Research, vol. 34, no. 21, pp. 6170-6182, 2006.

[94] M. F. Ullah, "Cancer multidrug resistance (MDR): a major impediment to effective chemotherapy," Asian Pacific Journal of Cancer Prevention, vol. 9, no. 1, pp. 1-6, 2008.
[95] B. Sarkadi, L. Homolya, G. Szakács, and A. Váradi, "Human multidrug resistance $\mathrm{ABCB}$ and ABCG transporters: participation in a chemoimmunity defense system," Physiological Reviews, vol. 86, no. 4, pp. 1179-1236, 2006.

[96] L. Ait M'Barek, H. Ait Mouse, A. Jaâfari et al., "Cytotoxic effect of essential oil of thyme (Thymus broussonettii) on the IGROV1 tumor cells resistant to chemotherapy," Brazilian Journal of Medical and Biological Research, vol. 40, no. 11, pp. 1537-1544, 2007.

[97] M. Abdel-Aziz, Y. Badr, N. Kamal, and E. H. El-Khatib, "In-vivo combined effect of cypermethrin and diode laser irradiation: comet assay measurements of DNA damage in rat liver cells," Arab Journal of Biotechnology, vol. 8, no. 2, pp. 293-306, 2005.

[98] A. M. Saab, A. Guerrini, G. Sacchetti et al., "Phytochemical analysis and cytotoxicity towards multidrug-resistant leukemia cells of essential oils derived from lebanese medicinal plants," Planta Medica, vol. 78, no. 18, pp. 1927-1931, 2012.

[99] A. Calcabrini, A. Stringaro, L. Toccacieli et al., “Terpinen-4ol, the main component of Melaleuca alternifolia (tea tree) oil inhibits the in vitro growth of human melanoma cells," Journal of Investigative Dermatology, vol. 122, no. 2, pp. 349-360, 2004.

[100] R. Ravizza, M. B. Gariboldi, R. Molteni, and E. Monti, "Linalool, a plant-derived monoterpene alcohol, reverses doxorubicin resistance in human breast adenocarcinoma cells," Oncology Reports, vol. 20, no. 3, pp. 625-630, 2008.

[101] A. Erdogan and A. Ozkan, "A comparative study of cytotoxic, membrane and DNA damaging effects of Origanum majorana's essential oil and its oxygenated monoterpene component linalool on parental and epirubicin-resistant H1299 cells," Biologia, vol. 68, no. 4, pp. 754-761, 2013.

[102] K. Effenberger-Neidnicht and R. Schobert, "Combinatorial effects of thymoquinone on the anti-cancer activity of doxorubicin," Cancer Chemotherapy and Pharmacology, vol. 67, no. 4, pp. 867-874, 2011.

[103] E.-S. A. Arafa, Q. Zhu, Z. I. Shah et al., “Thymoquinone up-regulates PTEN expression and induces apoptosis in doxorubicinresistant human breast cancer cells," Mutation Research-Fundamental and Molecular Mechanisms of Mutagenesis, vol. 706, no. 1-2, pp. 28-35, 2011.

[104] N. Hadfield, "The role of aromatherapy massage in reducing anxiety in patients with malignant brain tumours," International journal of palliative nursing, vol. 7, no. 6, pp. 279-285, 2001.

[105] S. M. Kite, E. J. Maher, K. Anderson et al., "Development of an aromatherapy service at a cancer centre," Palliative Medicine, vol. 12, no. 3, pp. 171-180, 1998.

[106] J. M. Koeller, M. S. Aapro, R. J. Gralla et al., "Antiemetic guidelines: creating a more practical treatment approach," Supportive Care in Cancer, vol. 10, no. 7, pp. 519-522, 2002.

[107] Z. Tayarani-Najaran, E. Talasaz-Firoozi, R. Nasiri, N. Jalali, and M. K. Hassanzadeh, "Antiemetic activity of volatile oil from Mentha spicata and Mentha piperita in chemotherapy-induced nausea and vomiting," ecancermedicalscience, vol. 7, no. 1, article 290, 2013.

[108] W. Maddocks-Jennings, J. M. Wilkinson, H. M. Cavanagh, and D. Shillington, "Evaluating the effects of the essential oils Leptospermum scoparium (manuka) and Kunzea ericoides (kanuka) on radiotherapy induced mucositis: a randomized, placebo controlled feasibility study," European Journal of Oncology Nursing, vol. 13, no. 2, pp. 87-93, 2009.

[109] M. E. Haisfield-Wolfe and C. Rund, "Malignant cutaneous wounds: a management protocol," Ostomy/wound management, vol. 43, no. 1, pp. 56-66, 1997. 
[110] P. H. Warnke, E. Sherry, P. A. J. Russo et al., "Antibacterial essential oils in malodorous cancer patients: clinical observations in 30 patients," Phytomedicine, vol. 13, no. 7, pp. 463-467, 2006.

[111] K. Soden, K. Vincent, S. Craske, C. Lucas, and S. Asley, "A randomized controlled trial of aromatherapy massage in a hospice setting," Palliative Medicine, vol. 18, no. 2, pp. 87-92, 2004.

[112] G. A. Fawzy, H. Y. Al Ati, and A. A. El Gamal, "Chemical composition and biological evaluation of essential oils of Pulicaria jaubertii," Pharmacognosy Magazine, vol. 9, no. 33, pp. 28-32, 2013.

[113] Y. Chen, C. Zhou, Z. Ge et al., "Composition and potential anticancer activities of essential oils obtained from myrrh and frankincense," Oncology Letters, vol. 6, no. 4, pp. 1140-1146, 2013.

[114] S. Stone, F. Vasconcellos, E. Lenardão, R. do Amaral, R. Jacob, and F. L. Leite, "Evaluation of potential use of Cymbopogon sp. essential oils, (R)-citronellal and N-citronellylamine in cancer chemotherapy," International Journal of Applied Research in Natural Products, vol. 6, no. 4, pp. 11-15, 2013.

[115] A. Russo, C. Formisano, D. Rigano et al., "Chemical composition and anticancer activity of essential oils of Mediterranean sage (Salvia officinalis L.) grown in different environmental conditions," Food and Chemical Toxicology, vol. 55, pp. 42-47, 2013.

[116] E. B. P. da Silva, A. L. Matsuo, C. R. Figueiredo, M. H. Chaves, P. Sartorelli, and J. H. G. Lago, "Chemical constituents and cytotoxic evaluation of essential oils from leaves of Porcelia macrocarpa (Annonaceae)," Natural Product Communications, vol. 8, no. 2, pp. 277-279, 2013.

[117] E. Cetinus, T. Temiz, M. Ergül, A. Altun, Ş. Çetinus, and T. Kaya, "Thyme essential oil inhibits proliferation of DLD-1 colorectal cancer cells through antioxidant effect," Cumhuriyet Medical Journal, vol. 35, no. 1, pp. 14-24, 2013.

[118] M. B. Majnooni, T. Ahmadi-Jouibari, M. R. Nikbakht, K. Mansouri, and G. Bahram, "Chemical composition and cytotoxic activity of the essential oil from Achillea wilhelmsii C. Koch," Journal of Reports in Pharmaceutical Sciences, vol. 2, no. 2, pp. 9-13, 2013.

[119] S. Shahabipour, O. Firuzi, M. Asadollahi, E. Faghihmirzaei, and K. Javidnia, "Essential oil composition and cytotoxic activity of Ducrosia anethifolia and Ducrosia flabellifolia from iran," Journal of Essential Oil Research, vol. 25, no. 2, pp. 160-163, 2013.

[120] R. P. C. Ferraz, G. M. B. Cardoso, T. B. da Silva et al., "Antitumour properties of the leaf essential oil of Xylopia frutescens Aubl (Annonaceae)," Food Chemistry, vol. 141, no. 1, pp. 196200, 2013.

[121] M. S. Owolabi, A. L. Ogundajo, N. S. Dosoky, and W. N. Setzer, "The cytotoxic activity of Annona muricata leaf oil from Badagary, Nigeria," The American Journal of Essential Oil and Natural Product, vol. 1, no. 1, pp. 1-3, 2013.

[122] S. Afoulous, H. Ferhout, E. G. Raoelison et al., "Chemical composition and anticancer, antiinflammatory, antioxidant and antimalarial activities of leaves essential oil of Cedrelopsis grevei," Food and Chemical Toxicology, vol. 56, pp. 352-362, 2013.

[123] S. Shahabipour, O. Firuzi, M. Asadollahi, M. Miri, and K. Javidnia, "Essential oil composition and cytotoxic activity of Libanotis transcaucasica schischk from Iran," Natural Products Chemistry \& Research, vol. 1, no. 108, pp. 1-2, 2013.
[124] F. S. Sharopov, M. Wink, D. R. Khalifaev, H. Zhang, N. S. Dosoky, and W. N. Setzer, "Composition and bioactivity of the essential oil of Melissa officinalis L. growing wild in Tajikistan," International Journal of Traditional and Natural Medicines, vol. 2, no. 2, pp. 86-96, 2013.

[125] I. Sadeghi, M. Yousefzadi, M. Behmanesh, M. Sharifi, and A. Moradi, "In vitro cytotoxic and antimicrobial activity of essential oil from Satureja Intermedia," Iranian Red Crescent Medical Journal, vol. 15, no. 1, pp. 70-74, 2012.

[126] N. F. do Eraldo, R. P. C. Ferraz, A. C. S. Britto et al., "Antitumor effect of the essential oil from leaves of Guatteria pogonopus (Annonaceae)," Chemistry and Biodiversity, vol. 10, no. 4, pp. 722-729, 2013.

[127] A. Erdogan and A. Ozkan, "Effects of Thymus revolutus Célak essential oil and its two major components on HepG2 cells membrane," Biologia, vol. 68, no. 1, pp. 105-111, 2013.

[128] R. B. Bostancioĝlu, M. Kürkçüoĝlu, K. H. C. Başer, and A. T. Koparal, "Assessment of anti-angiogenic and anti-tumoral potentials of Origanum onites L. essential oil," Food and Chemical Toxicology, vol. 50, no. 6, pp. 2002-2008, 2012.

[129] T. Kulisic-Bilusic, I. Schmöller, K. Schnäbele, L. Siracusa, and G. Ruberto, "The anticarcinogenic potential of essential oil and aqueous infusion from caper (Capparis spinosa L.)," Food Chemistry, vol. 132, no. 1, pp. 261-267, 2012.

[130] H. J. Harzallah, R. Grayaa, W. Kharoubi, A. Maaloul, M. Hammami, and T. Mahjoub, "Thymoquinone, the Nigella sativa bioactive compound, prevents circulatory oxidative stress caused by 1,2-dimethylhydrazine in erythrocyte during colon postinitiation carcinogenesis," Oxidative medicine and cellular longevity, vol. 2012, Article ID 854065, 6 pages, 2012.

[131] S. Sertel, T. Eichhorn, P. K. Plinkert, and T. Efferth, "Cytotoxicity of Thymus vulgaris essential oil towards human oral cavity squamous cell carcinoma," Anticancer Research, vol. 31, no. 1, pp. 8187, 2011.

[132] V. Dwivedil, R. Shrivastaval, S. Hussain, C. Ganguly, and M. Bharadwaj, "Comparative anticancer potential of clove (Syzygium aromaticum) —an Indian spice-against cancer cell lines of various anatomical origin," Asian Pacific Journal of Cancer Prevention, vol. 12, no. 8, pp. 1989-1993, 2011.

[133] T. Nagappan, P. Ramasamy, M. E. A. Wahid, T. C. Segaran, and C. S. Vairappan, "Biological activity of carbazole alkaloids and essential oil of Murraya koenigii against antibiotic resistant microbes and cancer cell lines," Molecules, vol. 16, no. 11, pp. 9651-9664, 2011.

[134] A. El Hadri, M. G. Del Río, J. Sanz et al., "Cytotoxic activity of $\alpha$-humulene and transcaryophyllene from Salvia officinalis in animal and human tumor cells," Anales de la Real Academia Nacional de Farmacia, vol. 76, no. 3, pp. 343-356, 2010.

[135] J. Z. Al-Kalaldeh, R. Abu-Dahab, and F. U. Afifi, "Volatile oil composition and antiproliferative activity of Laurus nobilis, Origanum syriacum, Origanum vulgare, and Salvia triloba against human breast adenocarcinoma cells," Nutrition Research, vol. 30, no. 4, pp. 271-278, 2010.

[136] H. Bendaoud, M. Romdhane, J. P. Souchard, S. Cazaux, and J. Bouajila, "Chemical composition and anticancer and antioxidant activities of Schinus molle L. and Schinus molle Raddi berries essential oils," Journal of Food Science, vol. 75, no. 6, pp. C466-C472, 2010.

[137] M. Sharma, S. K. Agrawal, P. R. Sharma, B. S. Chadha, M. K. Khosla, and A. K. Saxena, "Cytotoxic and apoptotic activity of essential oil from Ocimum viride towards COLO 205 cells," Food and Chemical Toxicology, vol. 48, no. 1, pp. 336-344, 2010. 
[138] M. Unlu, E. Ergene, G. V. Unlu, H. S. Zeytinoglu, and N. Vural, "Composition, antimicrobial activity and in vitro cytotoxicity of essential oil from Cinnamomum zeylanicum Blume (Lauraceae)," Food and Chemical Toxicology, vol. 48, no. 11, pp. 32743280, 2010.

[139] A. A. Mohamed, G. A. El-Emary, and H. F. Ali, "Influence of some Citrus essential oils on cell viability, glutathione-Stransferase and lipid peroxidation in Ehrlich ascites carcinoma cells," Journal of American Science, vol. 6, no. 10, pp. 820-826, 2010.

[140] T. Patharakorn, T. Arpornsuwan, N. Wetprasit, A. Promboon, and S. Ratanapo, "Antibacterial activity and cytotoxicity of the leaf essential oil of Morus rotunbiloba Koidz," Journal of Medicinal Plants Research, vol. 4, no. 9, pp. 837-843, 2010.

[141] Y. Yang, Y. Yue, Y. Runwei, and Z. Guolin, "Cytotoxic, apoptotic and antioxidant activity of the essential oil of Amomum tsao-ko," Bioresource Technology, vol. 101, no. 11, pp. 4205-4211, 2010.

[142] H. C. Yan, P. Hong, Z. Z. Yu, and S. Jing, "Evaluation of antioxidant and antitumour activities of lemon essential oil," Journal of Medicinal Plants Research, vol. 4, no. 18, pp. 1910-1915, 2010.

[143] A. I. Hussain, F. Anwar, S. A. S. Chatha, A. Jabbar, S. Mahboob, and P. S. Nigam, "Rosmarinus officinalis essential oil: antiproliferative, antioxidant and antibacterial activities," Brazilian Journal of Microbiology, vol. 41, no. 4, pp. 1070-1078, 2010.

[144] L. S. Yazan, J. B. Foo, S. A. A. Ghafar, K. W. Chan, P. M. Tahir, and M. Ismail, "Effect of kenaf seed oil from different ways of extraction towards ovarian cancer cells," Food and Bioproducts Processing, vol. 89, no. 4, pp. 328-332, 2011.

[145] D. P. Bezerra, J. D. B. Marinho Filho, A. P. N. N. Alves et al., "Antitumor activity of the essential oil from the leaves of Croton regelianus and its component ascaridole," Chemistry and Biodiversity, vol. 6, no. 8, pp. 1224-1231, 2009.

[146] J. R. Patil, G. K. Jayaprakasha, K. N. Chidambara Murthy, S. E. Tichy, M. B. Chetti, and B. S. Patil, "Apoptosis-mediated proliferation inhibition of human colon cancer cells by volatile principles of Citrus aurantifolia," Food Chemistry, vol. 114, no. 4, pp. 1351-1358, 2009.

[147] F. Conforti, F. Menichini, C. Formisano et al., "Comparative chemical composition, free radical-scavenging and cytotoxic properties of essential oils of six Stachys species from different regions of the Mediterranean Area," Food Chemistry, vol. 116, no. 4, pp. 898-905, 2009.

[148] Y. L. Li, C. M. Yeung, L. C. M. Chiu, Y.-Z. Cen, and V. E. C. Ooi, "Chemical composition and antiproliferative activity of essential oil from the leaves of a medicinal herb, Scheffera heptaphylla," Phytotherapy Research, vol. 23, no. 1, pp. 140-142, 2009.

[149] A. C. Mesa-Arango, J. Montiel-Ramos, B. Zapata, C. Durán, L. Betancur-Galvis, and E. Stashenko, "Citral and carvone chemotypes from the essential oils of Colombian Lippia alba (Mill.) N.E. Brown: composition, cytotoxicity and antifungal activity," Memorias do Instituto Oswaldo Cruz, vol. 104, no. 6, pp. 878-884, 2009.

[150] V. F. Péres, D. J. Moura, A. R. M. Sperotto et al., "Chemical composition and cytotoxic, mutagenic and genotoxic activities of the essential oil from Piper gaudichaudianum Kunth leaves," Food and Chemical Toxicology, vol. 47, no. 9, pp. 2389-2395, 2009.

[151] S. A. Fayed, "Antioxidant and anticancer activities of Citrus reticulate (Petitgrain Mandarin) and Pelargonium graveolens (Geranium) essential oils," Research Journal of Agriculture and Biological Sciences, vol. 5, no. 5, pp. 740-747, 2009.
[152] Y. T. Tung, M. T. Chua, S. Y. Wang, and S. T. Chang, "Antiinflammation activities of essential oil and its constituents from indigenous cinnamon (Cinnamomum osmophloeum) twigs," Bioresource Technology, vol. 99, no. 9, pp. 3908-3913, 2008.

[153] H. M. Ashour, "Antibacterial, antifungal, and anticancer activities of volatile oils and extracts from stems, leaves, and flowers of Eucalyptus sideroxylon and Eucalyptus torquata," Cancer Biology and Therapy, vol. 7, no. 3, pp. 399-403, 2008.

[154] C. Diaz, S. Quesada, O. Brenes, G. Aguilar, and J. F. Ciccio, "Chemical composition of Schinus molle essential oil and its cytotoxic activity on tumour cell lines," Natural Product Research, vol. 22, no. 17, pp. 1521-1534, 2008.

[155] J. Lei, J. Yu, H. Yu, and Z. Liao, "Composition, cytotoxicity and antimicrobial activity of essential oil from Dictamnus dasycarpus," Food Chemistry, vol. 107, no. 3, pp. 1205-1209, 2008.

[156] M. R. Loizzo, R. Tundis, F. Menichini, A. M. Saab, G. A. Statti, and F. Menichini, "Cytotoxic activity of essential oils from Labiatae and Lauraceae families against in vitro human tumor models," Anticancer Research, vol. 27, no. 5, pp. 3293-3299, 2007.

[157] S. A. El-Sawi, H. M. Motawae, and A. M. Ali, "Chemical composition, cytotoxic activity and antimicrobial activity of essential oils of leaves and berries of Juniperus phoenicea L. grown in Egypt," African Journal of Traditional, Complementary and Alternative Medicines, vol. 4, no. 4, pp. 417-426, 2007.

[158] S. L. da Silva, P. M. Figueiredo, and T. Yano, "Cytotoxic evaluation of essential oil from Zanthoxylum rhoifolium Lam. leaves," Acta Amazonica, vol. 37, no. 2, pp. 281-286, 2007.

[159] J. Hou, T. Sun, J. Hu, S. Chen, X. Cai, and G. Zou, "Chemical composition, cytotoxic and antioxidant activity of the leaf essential oil of Photinia serrulata," Food Chemistry, vol. 103, no. 2, pp. 355-358, 2007.

[160] E. Bieberich, A. Sebastian, and N. H. Sarkar, "Neem-seed oil inhibits the growth of breast cancer cells," Proceedings of the American Association for Cancer Research, vol. 2006, no. 1, article 456, 2006.

[161] M. A. Apel, M. E. L. Lima, A. Souza et al., "Screening of the biological activity from essential oils of native species from the Atlantic Rainforest (São Paulo-Brazil)," Pharmacologyonline (Salerno), vol. 3, pp. 376-383, 2006.

[162] J. Manosroi, P. Dhumtanom, and A. Manosroi, "Anti-proliferative activity of essential oil extracted from Thai medicinal plants on KB and P388 cell lines," Cancer Letters, vol. 235, no. 1, pp. 114-120, 2006.

[163] H. Loutrari, S. Magkouta, A. Pyriochou et al., "Mastic oil from Pistacia lentiscus var. chia inhibits growth and survival of human K562 leukemia cells and attenuates angiogenesis," Nutrition and Cancer, vol. 55, no. 1, pp. 86-93, 2006.

[164] R. Monajemi, S. Oryan, A. Haeri-Roohani, A. Ghannadi, and A. Jafarian, "Cytotoxic effects of essential oils of some Iranian Citrus peels," Iranian Journal of Pharmaceutical Research, pp. 183-187, 2010.

[165] C. B. Yoo, K. T. Han, K. S. Cho et al., "Eugenol isolated from the essential oil of Eugenia caryophyllata induces a reactive oxygen species-mediated apoptosis in HL-60 human promyelocytic leukemia cells," Cancer Letters, vol. 225, no. 1, pp. 41-52, 2005.

[166] M. Sylvestre, J. Legault, D. Dufour, and A. Pichette, "Chemical composition and anticancer activity of leaf essential oil of Myrica gale L," Phytomedicine, vol. 12, no. 4, pp. 299-304, 2005.

[167] J. Legault, W. Dahl, E. Debiton, A. Pichette, and J.-C. Madelmont, "Antitumor activity of balsam fir oil: production of reactive oxygen species induced by $\alpha$-humulene as possible mechanism of action," Planta Medica, vol. 69, no. 5, pp. 402-407, 2003. 
[168] A. C. Gören, G. Topçu, G. Bilsel, M. Bilsel, Z. Aydoğmuş, and J. M. Pezzuto, "The chemical constituents and biological activity of essential oil of Lavandula stoechas ssp. stoechas," Zeitschrift für Naturforschung C: Journal of Biosciences, vol. 57, no. 9-10, pp. 797-800, 2002.

[169] L. T. Bidinotto, C. A. R. A. Costa, D. M. F. Salvadori, M. Costa, M. A. M. Rodrigues, and L. F. Barbisan, "Protective effects of lemongrass (Cymbopogon citratus STAPF) essential oil on DNA damage and carcinogenesis in female Balb/C mice," Journal of Applied Toxicology, vol. 31, no. 6, pp. 536-544, 2011.

[170] A. Manjamalai and V. M. B. Grace, "The chemotherapeutic effect of essential oil of Plectranthus amboinicus (Lour) on lung metastasis developed by B16F-10 cell line in C57BL/6 mice," Cancer investigation, vol. 31, no. 1, pp. 74-82, 2013.

[171] W. Chen, Y. Lu, M. Gao, J. Wu, A. Wang, and R. Shi, "Anti-angiogenesis effect of essential oil from Curcuma zedoaria in vitro and in vivo," Journal of Ethnopharmacology, vol. 133, no. 1, pp. 220-226, 2011.

[172] G. H. Kumar, R. Vidya Priyadarsini, G. Vinothini, P. Vidjaya Letchoumy, and S. Nagini, "The neem limonoids azadirachtin and nimbolide inhibit cell proliferation and induce apoptosis in an animal model of oral oncogenesis," Investigational New Drugs, vol. 28, no. 4, pp. 392-401, 2010.

[173] R. V. Priyadarsini, R. S. Murugan, P. Sripriya, D. Karunagaran, and S. Nagini, "The neem limonoids azadirachtin and nimbolide induce cell cycle arrest and mitochondria-mediated apoptosis in human cervical cancer (HeLa) cells," Free Radical Research, vol. 44, no. 6, pp. 624-634, 2010.

[174] R. V. Priyadarsini, P. Manikandan, G. H. Kumar, and S. Nagini, "The neem limonoids azadirachtin and nimbolide inhibit hamster cheek pouch carcinogenesis by modulating xenobioticmetabolizing enzymes, DNA damage, antioxidants, invasion and angiogenesis," Free Radical Research, vol. 43, no. 5, pp. 492504, 2009.

[175] S. J. Mehdi, A. Ahmad, M. Irshad, N. Manzoor, and M. M. A. Rizvi, "Cytotoxic effect of Carvacrol on human cervical cancer cells," Biology and Medicine, vol. 3, no. 2, pp. 307-312, 2011.

[176] Q. H. Yin, F. X. Yan, X. Y. Zu et al., "Anti-proliferative and pro-apoptotic effect of carvacrol on human hepatocellular carcinoma cell line HepG-2," Cytotechnology, vol. 64, no. 1, pp. 43-51, 2012.

[177] A. T. Koparal and M. Zeytinoglu, "Effects of carvacrol on a human non-small cell lung cancer (NSCLC) cell line, A549," Cytotechnology, vol. 43, no. 1-3, pp. 149-154, 2003.

[178] K. M. Arunasree, "Anti-proliferative effects of carvacrol on a human metastatic breast cancer cell line, MDA-MB 231," Phytomedicine, vol. 17, no. 8, pp. 581-588, 2010.

[179] J. E. Okokon, A. Dar, and M. I. Choudhary, "Immunomodulatory, cytotoxic and antileishmanial activity of phytoconstituents of Croton zambesicus," Phytopharmacology Journal, vol. 4, no. 1, pp. 31-40, 2013.

[180] S. S. Jia, G. P. Xi, M. Zhang et al., "Induction of apoptosis by Dlimonene is mediated by inactivation of Akt in LS174T human colon cancer cells," Oncology Reports, vol. 29, no. 1, pp. 349-354, 2013.

[181] L. Tao, L. Zhou, L. Zheng, and M. Yao, "Elemene displays anticancer ability on laryngeal cancer cells in vitro and in vivo," Cancer Chemotherapy and Pharmacology, vol. 58, no. 1, pp. 2434, 2006.

[182] F. C. Huang, Y. Fan, and S. Zheng, "Effect of elemene on the telomerase activity, apoptosis and cell cycles of the colon cancer lovo cell line," Herald of Medicine, vol. 10, pp. 713-715, 2004.
[183] R. Ghosh, N. Nadiminty, J. E. Fitzpatrick, W. L. Alworth, T. J. Slaga, and A. P. Kumar, "Eugenol causes melanoma growth suppression through inhibition of E2F1 transcriptional activity," Journal of Biological Chemistry, vol. 280, no. 7, pp. 5812-5819, 2005.

[184] P. Manikandan, G. Vinothini, R. Vidya Priyadarsini, D. Prathiba, and S. Nagini, "Eugenol inhibits cell proliferation via NF$\kappa \mathrm{B}$ suppression in a rat model of gastric carcinogenesis induced by MNNG," Investigational New Drugs, vol. 29, no. 1, pp. 110-117, 2011.

[185] A. Carrasco, C. Espinoza, V. Cardile et al., "Eugenol and its synthetic analogues inhibit cell growth of human cancer cells (Part I)," Journal of the Brazilian Chemical Society, vol. 19, no. 3, pp. 543-548, 2008.

[186] S. S. Kim, O. J. Oh, H. Y. Min et al., "Eugenol suppresses cyclooxygenase-2 expression in lipopolysaccharide-stimulated mouse macrophage RAW264.7 cells," Life Sciences, vol. 73, no. 3, pp. 337-348, 2003.

[187] S. K. Jaganathan, A. Mazumdar, D. Mondhe, and M. Mandal, "Apoptotic effect of eugenol in human colon cancer cell lines," Cell Biology International, vol. 35, no. 6, pp. 607-615, 2011.

[188] B. B. R. Choi, S. H. Shin, U. K. Kim, J. W. Hong, and G. C. S. Kim, "Phase cell cycle arrest and apoptosis is induced by eugenol in G361 human melanoma cells," International Journal of Oral Biology, vol. 36, no. 3, pp. 129-134, 2011.

[189] Y. Xiao, F. Q. Yang, S. P. Li et al., "Furanodiene induces $\mathrm{G}_{2} /$ $\mathrm{M}$ cell cycle arrest and apoptosis through MAPK signaling and mitochondria-caspase pathway in human hepatocellular carcinoma cells," Cancer Biology and Therapy, vol. 6, no. 7, pp. 10441050, 2007.

[190] S. Carnesecchi, A. Bradaia, B. Fischer et al., "Perturbation by geraniol of cell membrane permeability and signal transduction pathways in human colon cancer cells," Journal of Pharmacology and Experimental Therapeutics, vol. 303, no. 2, pp. 711-715, 2002.

[191] P. Srivastava, N. Yadav, R. Lella et al., "Neem oil limonoids induces p53-independent apoptosis and autophagy," Carcinogenesis, vol. 33, no. 11, pp. 2199-2207, 2012.

[192] S. C. Gupta, S. Prasad, D. R. Sethumadhavan, M. S. Nair, Y. Y. Mo, and B. B. Aggarwal, "Nimbolide, a limonoid triterpene, inhibits growth of human colorectal cancer xenografts by suppressing the proinflammatory microenvironment," Clinical Cancer Research, vol. 19, no. 16, pp. 4465-4476, 2013.

[193] K. Kavitha, R. Vidya Priyadarsini, P. Anitha et al., "Nimbolide, a neem limonoid abrogates canonical NF- $\kappa$ B and Wnt signaling to induce caspase-dependent apoptosis in human hepatocarcinoma (HepG2) cells," European Journal of Pharmacology, vol. 681, no. 1-3, pp. 6-14, 2012.

[194] S. Babykutty, P. S. Priya, R. J. Nandini et al., "Nimbolide retards tumor cell migration, invasion, and angiogenesis by downregulating MMP-2/9 expression via inhibiting ERK1/2 and reducing DNA-binding activity of NF- $\kappa \mathrm{B}$ in colon cancer cells," Molecular Carcinogenesis, vol. 51, no. 6, pp. 475-490, 2012.

[195] M. Jennifer Stark, Y. D. Burke, J. H. McKinzie, A. Siar Ayoubi, and P. L. Crowell, "Chemotherapy of pancreatic cancer with the monoterpene perillyl alcohol," Cancer Letters, vol. 96, no. 1, pp. 15-21, 1995.

[196] L. Yeruva, K. J. Pierre, A. Elegbede, R. C. Wang, and S. W. Carper, "Perillyl alcohol and perillic acid induced cell cycle arrest and apoptosis in non small cell lung cancer cells," Cancer Letters, vol. 257, no. 2, pp. 216-226, 2007. 
[197] S. J. Greay, D. J. Ireland, H. T. Kissick et al., "Induction of necrosis and cell cycle arrest in murine cancer cell lines by Melaleuca alternifolia (tea tree) oil and terpinen-4-ol," Cancer Chemotherapy and Pharmacology, vol. 65, no. 5, pp. 877-888, 2010.

[198] Q. H. Yin, Y. Z. Zhuang, and X. F. Yan, "Antitumor efficacy of thymol," Progress in Modern Biomedicine, vol. 11, article 028, 2010.

[199] N. El-Najjar, M. Chatila, H. Moukadem et al., "Reactive oxygen species mediate thymoquinone-induced apoptosis and activate ERK and JNK signaling," Apoptosis, vol. 15, no. 2, pp. 183-195, 2010.

[200] S. Santha, A. Bommareddy, B. Rule et al., "Antineoplastic effects of $\alpha$-santalol on estrogen receptor-positive and estrogen receptor-negative breast cancer cells through cell cycle arrest at $\mathrm{G}_{2} / \mathrm{M}$ phase and induction of apoptosis," PLoS ONE, vol. 8, no. 2, Article ID e56982, 2013.

[201] K. R. Park, D. Nam, H. M. Yun et al., “ $\beta$-Caryophyllene oxide inhibits growth and induces apoptosis through the suppression of $\mathrm{PI} 3 \mathrm{~K} / \mathrm{AKT} / \mathrm{mTOR} / \mathrm{S} 6 \mathrm{~K} 1$ pathways and ROS-mediated MAPKs activation," Cancer Letters, vol. 312, no. 2, pp. 178-188, 2011.

[202] J. Hu, W. Jin, and P. M. Yang, "Reversal of resistance to adriamycin in human breast cancer cell line MCF-7/ADM by betaelemene," Zhonghua Zhong Liu Za Zhi, vol. 26, no. 5, pp. 268270, 2004.

[203] X. S. Wu, T. Xie, J. Lin et al., "An investigation of the ability of elemene to pass through the blood-brain barrier and its effect on brain carcinomas," Journal of Pharmacy and Pharmacology, vol. 61, no. 12, pp. 1653-1656, 2009.

[204] J. Liu, X. J. Hu, B. Jin, X. J. Qu, K. Z. Hou, and Y. P. Liu, “ $\beta$-Elemene induces apoptosis as well as protective autophagy in human non-small-cell lung cancer A549 cells," Journal of Pharmacy and Pharmacology, vol. 64, no. 1, pp. 146-153, 2012.

[205] X. Li, G. Wang, J. Zhao et al., "Antiproliferative effect of $\beta$-elemene in chemoresistant ovarian carcinoma cells is mediated through arrest of the cell cycle at the $\mathrm{G}_{2}-\mathrm{M}$ phase," Cellular and Molecular Life Sciences, vol. 62, no. 7-8, pp. 894-904, 2005.

[206] Z. J. Dai, W. Tang, W. F. Lu et al., "Antiproliferative and apoptotic effects of $\beta$-elemene on human hepatoma HepG2 cells," Cancer Cell International, vol. 13, no. 1, article 27, 2013.

[207] K. Wu, J. Yang, and Y. Lan, "Induction of apoptosis by $\gamma$-humulene in HT29 human colorectal carcinoma cell lines," Planta Medica, vol. 76, no. 12, article P576, 2010. 

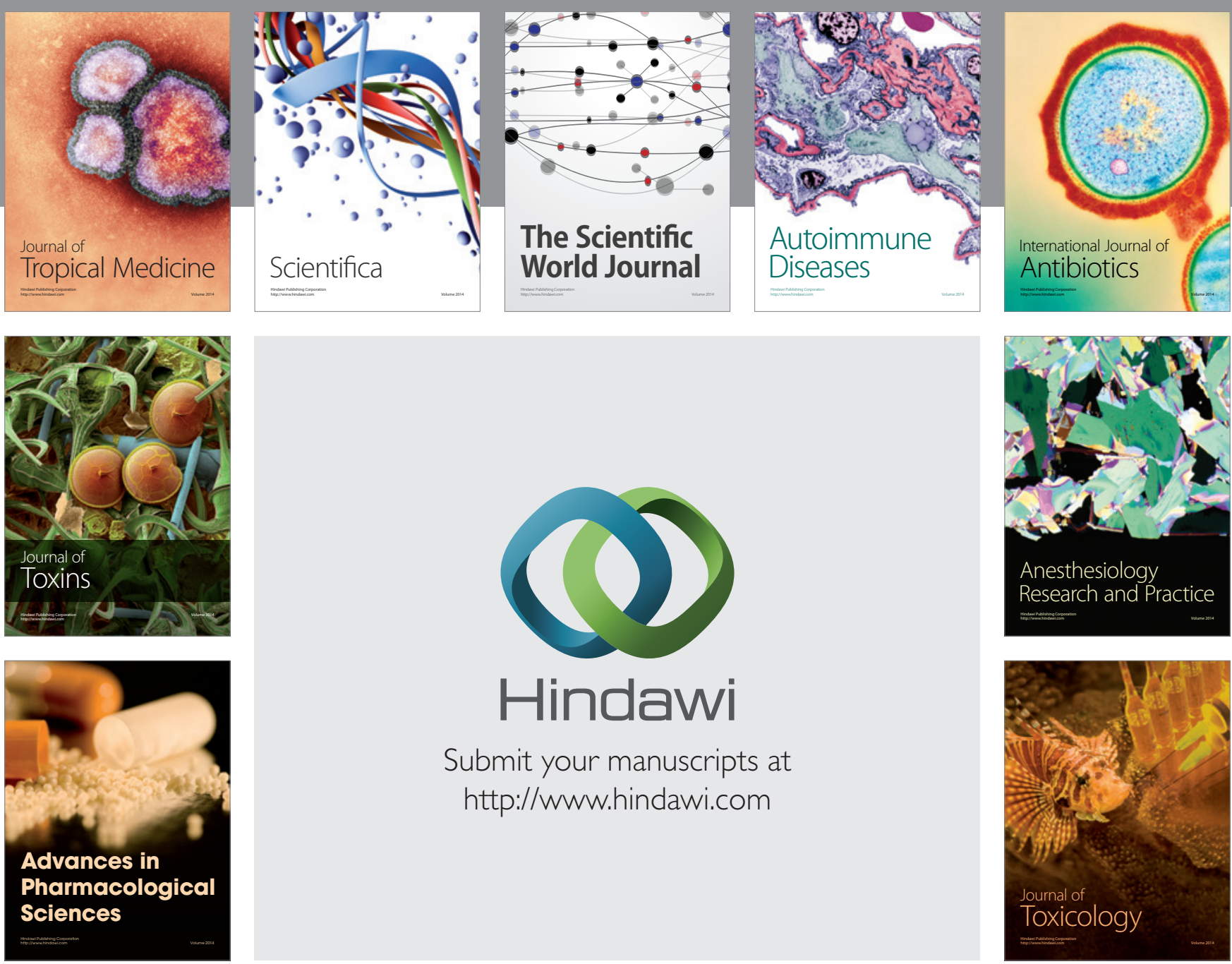

\section{Hindawi}

Submit your manuscripts at

http://www.hindawi.com
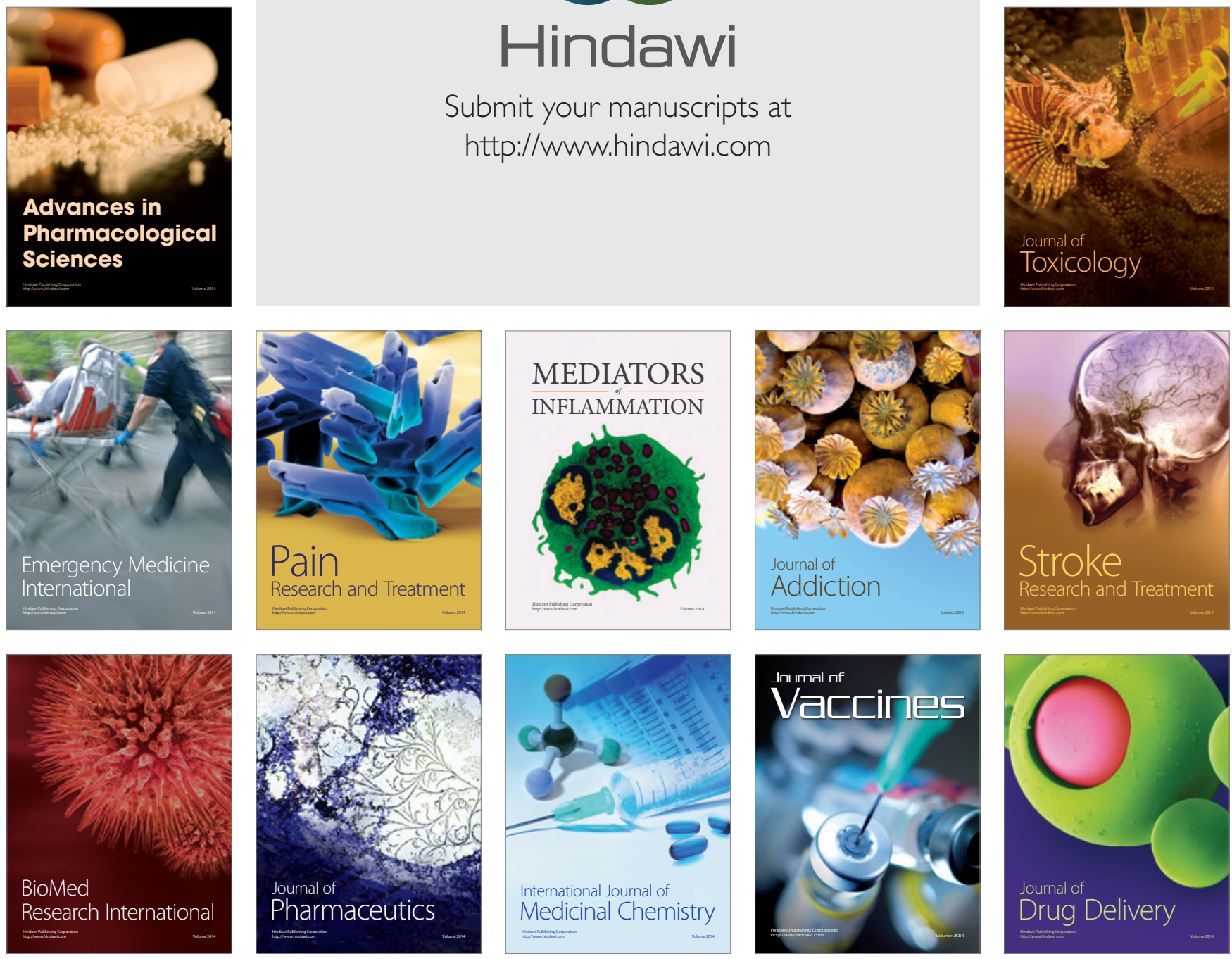